\title{
Current Limitations of Intraoperative Ultrasound in Brain Tumor Surgery
}

\author{
Andrej Šteňo *, Ján Buvala, Veronika Babková, Adrián Kiss, David Toma \\ and Alexander Lysak
}

Department of Neurosurgery, Comenius University, Faculty of Medicine, University Hospital Bratislava, Bratislava, Slovakia

While benefits of intraoperative ultrasound (IOUS) have been frequently described, data on IOUS limitations are relatively sparse. Suboptimal ultrasound imaging of some pathologies, various types of ultrasound artifacts, challenging patient positioning during some IOUS-guided surgeries, and absence of an optimal IOUS probe depicting the entire sellar region during transsphenoidal pituitary surgery are some of the most important pitfalls. This review aims to summarize prominent limitations of current IOUS systems, and to present possibilities to reduce them by using ultrasound technology suitable for a specific procedure and by proper scanning techniques. In addition, future trends of IOUS imaging optimization are described in this article.

Edited by:

Francesco DiMeco, Fondazione IRCCS Istituto Neurologio Carlo Besta, Italy

Reviewed by:

Llewellyn Padayachy, University of Pretoria, South Africa

Giuseppe Maria Della Pepa, Fondazione Policlinico Universitario Agostino Gemelli IRCSS, Italy

${ }^{*}$ Correspondence: Andrej Šteňo andrej.steno@fmed.uniba.sk

Specialty section: This article was submitted to Neuro-Oncology and Neurosurgical Oncology, a section of the journal Frontiers in Oncology

Received: 26 January 2021 Accepted: 03 March 2021 Published: 22 March 2021

Citation:

Šteňo A, Buvala J, Babková V, Kiss A, Toma D and Lysak A (2021) Current Limitations of Intraoperative Ultrasound in Brain Tumor Surgery. Front. Oncol. 11:659048. doi: 10.3389/fonc.2021.659048
Keywords: intraoperative ultrasound, artifacts, pitfalls, training, neurosurgery

\section{INTRODUCTION}

Standard conventional neuronavigation is a widespread tool for image guidance in brain tumor surgery. It has become standard of practice in many institutions for initial tumor localization, for surgical trajectory planning, and also for assessment of tumor margins during resection $(1,2)$. However, popularity of various intraoperative imaging methods continues to increase due to the well-known fact, that the accuracy of navigation may become unreliable after brain shift occurs $(1,3-5)$

Intraoperative ultrasound (IOUS) has been used during resection of brain tumors for over four decades since early 1980s (6). However, despite the initial enthusiasm, this intraoperative imaging modality was not widely accepted, especially until the end of the millennium. There were various reasons for initial lack of acceptance of IOUS. First, the image quality of older IOUS systems was low. Second, oblique 2D IOUS views were unfamiliar to many neurosurgeons, used to evaluate computer tomography (CT) and magnetic resonance imaging (MRI) brain scans in standard three orthogonal planes-axial, coronal and sagittal. Third, visualization of large lesions in their full extent was problematic due to limited field of view of 2D IOUS probes. Fourth, as standard B-mode ultrasound does not selectively depict the MRI-contrast enhancing portion of diffuse high-grade gliomas, it could not be used for reliable identification and subsequent resection of this most malignant, enhancing glioma tissue. Fifth, many surgeons refused to change their surgical habits and perform horizontal craniotomies only in order to enable sufficient filling of resection cavity with fluid and appropriate ultrasound scanning. Sixth, difficulties in visualizing the bottom of the resection cavity due to IOUS artifacts were repeatedly reported, and this often resulted in insufficient visualization of tumor residua in this area. Seventh, distinct visualization of the entire sellar region during transsphenoidal approach was challenging. 
Nowadays, some of these limitations can be minimized using modern IOUS equipment and proper methods of IOUS utilization. However, some pitfalls still persist, and solutions to overcome them are needed.

\section{SUBOPTIMAL ULTRASOUND IMAGING}

\section{Image Quality}

The main disadvantage of older two-dimensional (2D) IOUS systems was low image quality (7), mainly due to poor spatial resolution and dynamic range-identification of various brain structures was therefore challenging. Especially imaging of deeper structures such as thalamus and brainstem was insufficient, as low frequency probes of older IOUS systems offered very low spatial resolution. Insufficient imaging quality was evident especially when compared to MRI, which offered superior resolution and tissue differentiation (1).

Comparing to older devices, many new ultrasound systems have significantly better quality-one of the improvements is due to the ability of modern ultrasound systems to electronically and dynamically tune the frequency range of the imaging probe (8). Higher frequency means better image resolution, i.e. a better ability to differentiate two small targets as separate objects (8). However, the drawback of high frequency probes is the reduced penetration of acoustic waves in the tissue due to scattering and absorption (1), and thus insufficient visualization of deeper structures (8). As recommended by Unsgaard et al. (9), to obtain the best image, different probes should be used for imaging of lesions localized in different depth: a $5 \mathrm{MHz}(4-8 \mathrm{MHz})$ probe gives optimal image quality at a distance of $2.5-6 \mathrm{~cm}$ from the probe tip, while for superficial lesions a $12 \mathrm{MHz}$ linear probe is ideal as it provides the best image quality for the first few millimeters down to a depth of $4 \mathrm{~cm}$ (9). Using different probes for lesions at different depths in a series of 105 IOUS guidedsurgeries, Mair et al. (10) introduced a grading system of ultrasonographic visibility for various intracerebral pathologies. Lesions difficult to visualize, having no clear border with normal brain represent Grade 1; lesions clearly identifiable, but with no clear border with normal tissue represent Grade 2; and lesions clearly identifiable, and with clear border represent Grade 3 (Grade 0 was considered for lesions not identifiable by IOUS). Only $8 \%$ out of 105 lesions were evaluated as grade 1 , and none as grade 0 .

Very good IOUS visualization of various non-irradiated brain lesions was repeatedly reported-predominantly of intra-axial tumors like gliomas and metastases (11-14), as well as of extraaxial tumors like meningiomas $(11,15)$. However, in patients who had received radiotherapy, the quality of ultrasound image often decreases (16). As evaluated by histopathology, a high-end intraoperative ultrasound system was proven to depict glioma (pseudo)borders at least as distinctly as a three-dimensional (3D) T2-weighted MRI image and better than a 3D T1-weighted MRI image (12). When high frequency ultrasound linear probe was used, the accuracy of residual low-grade glioma tissue detection by IOUS imaging was described to be comparable to high-field intraoperative MRI (17).

Nevertheless, the newest and perhaps the most detailed data presented by leading Norwegian group showed that MRI is superior in pre-resectional glioma visualization (18) as well as in visualization of small tumor remnants (19). This finding is important (Figure 1) despite the fact that in some cases glioma tissue may be better visualized by IOUS, as compared to highfield MRI (Figure 2).

Interestingly, in spite of reports from prominent neurosurgical centers stating that small deep-seated perforating lenticulostriate arteries (LSAs) cannot be identified by IOUS Doppler imaging $(20,21)$, these perforators may be in fact depicted (22) by power-Doppler. Using proper methodology and high-end IOUS devices, LSAs may be at least in some patients visualized comparably to MRI (figure). Hence, IOUS power Doppler imaging may serve as an important adjunct during resection of insular gliomas (Figure 3) (22). However, prospective studies are needed to evaluate real effectiveness of this relatively new method of intraoperative LSAs identification.

\section{Anatomical Orientation and Large Lesions Visualization}

Most neurosurgeons have extensive experience with the interpretation of CT and MRI images in three orthogonal planes-axial, coronal and sagittal. However, 2D IOUS image is dependent on the orientation of the ultrasound probe, and achieving IOUS scans in at least two exact orthogonal planes may be challenging, especially in small craniotomies (23). Because intraoperative $2 \mathrm{D}$ ultrasound views are mostly oblique (24), many neurosurgeons with little or no training/expertise may have considerable orientation problems during 2D IOUS-guided surgeries (25). Understanding the $2 \mathrm{D}$ ultrasound image is difficult particularly in areas with no cysts or ventricles visible (24). Another 2D IOUS problem is represented by the fact that ultrasound probes have a limited field of view. It is possible to evaluate only a section of brain tissue during $2 \mathrm{D}$ ultrasound scanning, and visualization of large lesions in their whole extent may be problematic.

These pitfalls together with aforementioned suboptimal image quality of older 2D IOUS systems caused preferable use of frameless neuronavigation based on preoperative CT or MRI for brain tumor-surgery guidance by many neurosurgeons $(2$, 26-31). Unlike 2D IOUS, frameless neuronavigation displays normal and pathological tissue in three orthogonal planes, and also enables preoperative planning of the craniotomy placement and surgical trajectory direction. Only a minority of neurosurgical centers continued in regular 2D IOUS use, mostly because of significant inaccuracy of neuronavigation after the occurrence of brain-shift, considering the fact that $2 \mathrm{D}$ IOUS offers a real-time imaging and is unaffected by brain-shift. Others solved the brain-shift problem by using intraoperative MRI for navigation data update $(4,5,32)$; this solution however is much more expensive.

In order to simplify the interpretation of ultrasound imagery and allow quantification of brain-shift (33), some groups have 


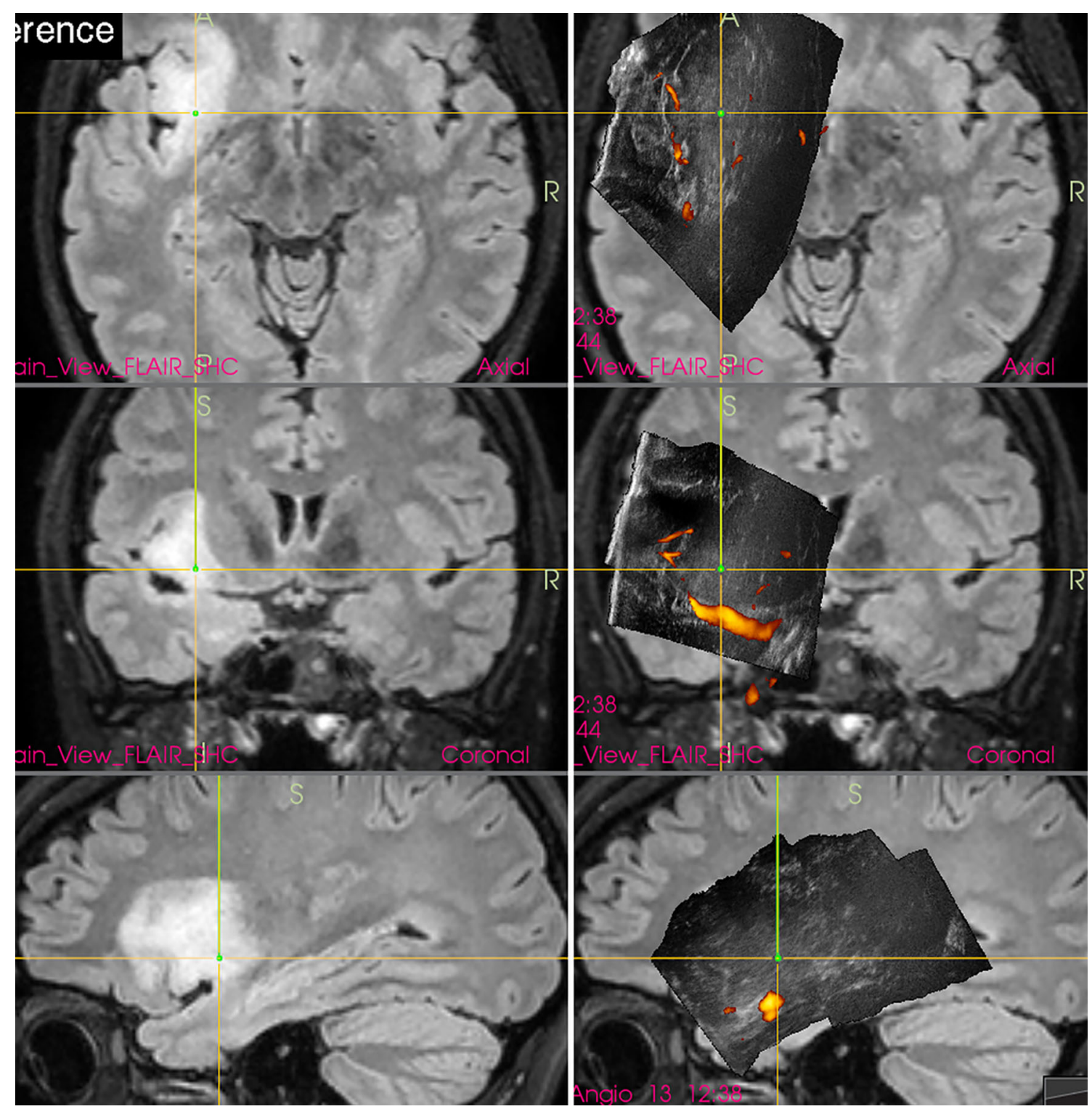

FIGURE 1 | Left-sided insular grade II astrocytoma (Left column) preoperative navigation 3D FLAIR MRI sequence (3-Tesla MRI scanner) (Right column) preresectional 3D IOUS image fused with navigation FLAIR MRI sequence. Note that the tumor tissue is only mildly hyperechoic and less distinctly visualized comparing to MRI. 3D, three-dimensional; IOUS, intraoperative ultrasound; FLAIR, fluid attenuated inversion recovery; MRI, magnetic resonance imaging.

connected ultrasound scanner to conventional neuronavigation, digitized the analog video signal from the scanner, and displayed a real-time $2 \mathrm{D}$ IOUS image on the navigation computer side by side with the corresponding MRI slice (Figure 4) (34-36). However, a much bigger step forward was the integration of neuronavigation and IOUS devices based on a digital interface between the ultrasound scanner and the navigation computer. This type of integration was the basis for the development of navigated 3D IOUS - a system that enables navigation using preoperative 3D MRI or CT data as well as intraoperative 3D ultrasound data (33). Three-dimensional ultrasound data is generated by summation of multiple $2 \mathrm{D}$ ultrasound images acquired by moving ultrasound probe freehand over the field of interest; the series of 2D IOUS images are then reconstructed to produce a $3 \mathrm{D}$ volume (37). These systems use ultrasound probes equipped with reflective marker reference frames and the position and orientation of the probe during the movement is tracked by means of a navigation camera system. After the scanning, 3D IOUS systems enable surgeons to visualize and navigate the whole volume of normal and pathological tissue that was scanned.

By means of combining frameless navigation with ultrasound, the navigated 3D IOUS systems solved prominent drawbacks of stand-alone conventional neuronavigation and 2D IOUS devices 

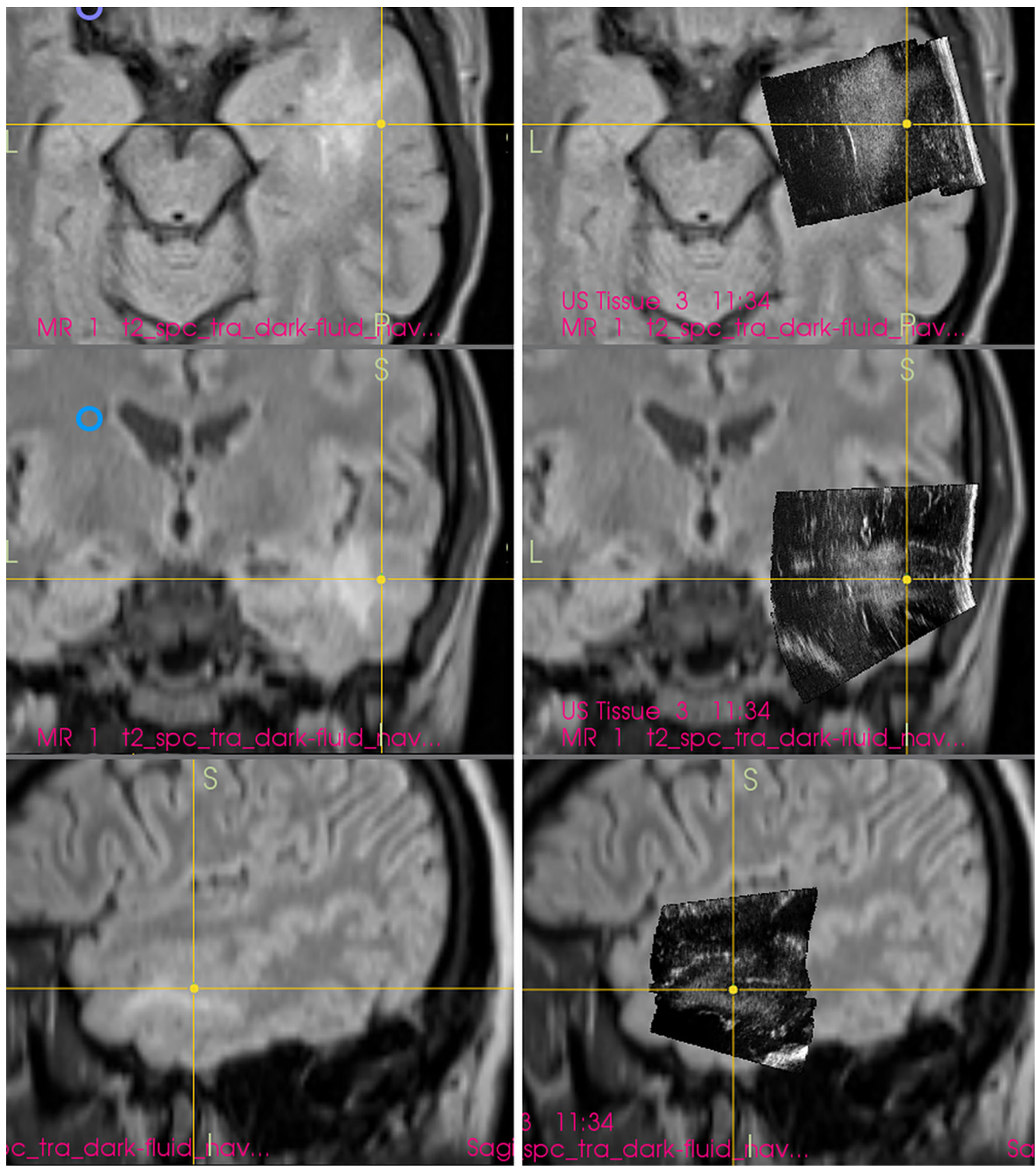

FIGURE 2 | Right-sided temporal grade II astrocytoma (Left column) preoperative navigation 3D FLAIR MRI sequence (1.5-Tesla MRI scanner) (Right column) pre-resectional 3D IOUS image fused with navigation FLAIR MRI sequence. Note that the hyperechoic tumor tissue is better visualized on IOUS image comparing to MRI. 3D, three-dimensional; FLAIR, fluid attenuated inversion recovery; MRI, magnetic resonance imaging; IOUS, intraoperative ultrasound.

- namely the brain-shift problem of navigation as well as the orientation and limited field of view problems of 2D IOUS (25). Even very large lesions, much larger than the ultrasound probe field of view, may be visualized in their whole extent using navigated 3D IOUS systems (Figure 5).

Automatic fusion with navigation MRI and/or CT sequence and rendering the ultrasound image in orthogonal planes make the recognition of normal and pathological structures much easier (38). In addition, navigated 3D IOUS provides almost real-time imaging and allows re-scanning of operating field as often as necessary, hence allows effective brain-shift compensation (25). Nevertheless, considering the fact that the "main" part of fused (combined) navigation-MRI/IOUS image is in fact ultrasound visualization of the operating field, knowledge of echogenicity of various normal and pathological brain structures is necessary. 

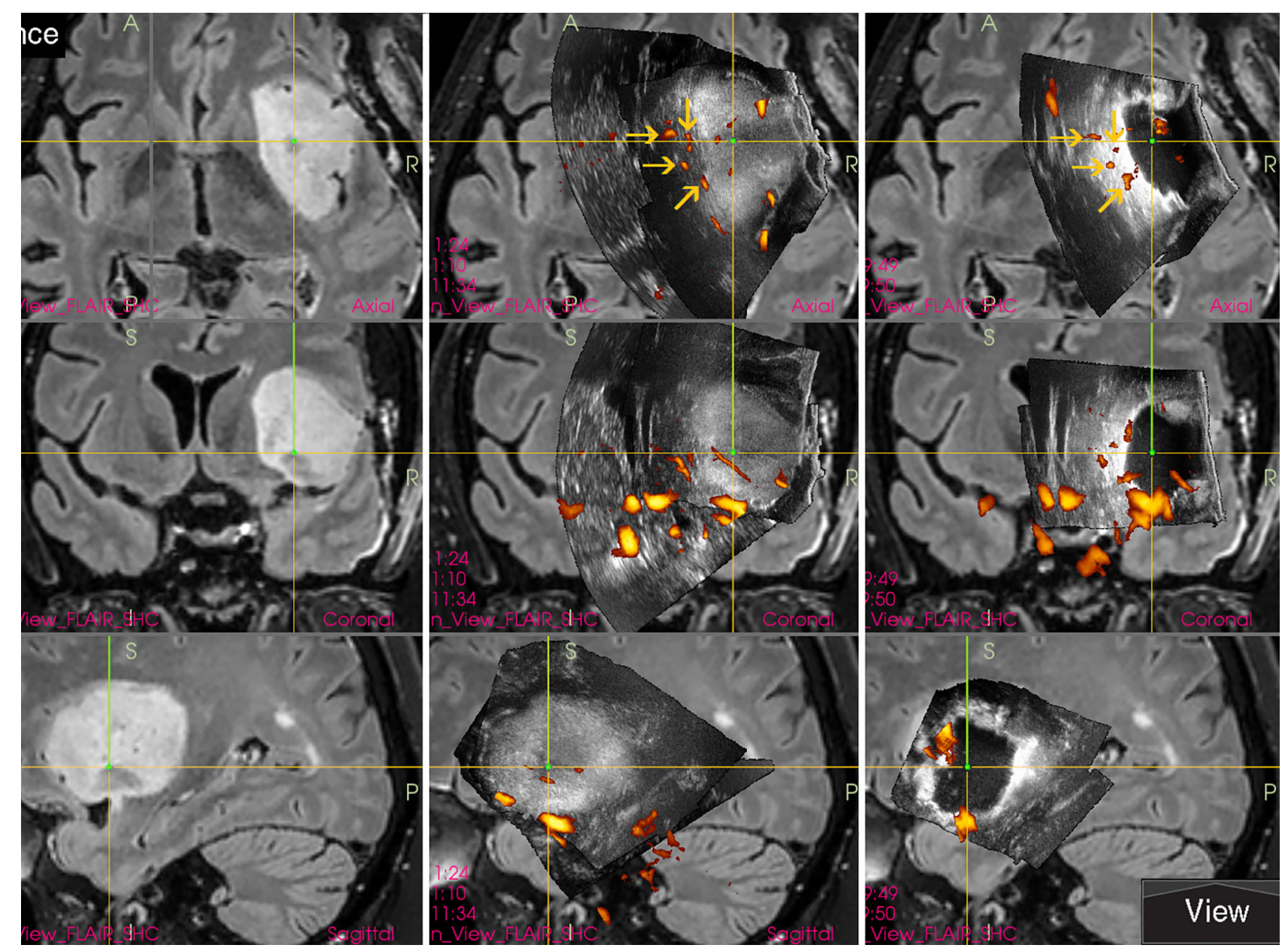

FIGURE 3 | Right-sided insular grade II astrocytoma (Left column) preoperative navigation 3D FLAIR MRI sequence (Middle column) pre-resectional 3D IOUS image fused with navigation FLAIR MRI sequence. Yellow arrows = lenticulostriate arteries visualized by 3D IOUS power-Doppler mode (Right column) 3D IOUS image acquired shortly before the end of resection. Note the close proximity of resection cavity bottom to the lenticulostriate arteries (arrows), intraoperative visualization of perforating arteries helped to prevent iatrogenic injury to them. 3D, three-dimensional; FLAIR, fluid attenuated inversion recovery; MRI, magnetic resonance imaging; IOUS, intraoperative ultrasound.

Another benefit of navigated 3D IOUS comparing to standard 2D IOUS is the fact that 3D IOUS is suitable for biopsies of deepseated supratentorial lesions, as showed by the group of Moiyadi (39).

\section{Selective Visualization of High-Grade Glioma Portion}

Gross-total resection of high-grade gliomas is usually defined as a complete removal of contrast-enhancing glioma tissue evaluated on postoperative contrast-enhanced T1-weighted MRI (40). However, standard 2D or 3D IOUS based on Bmode ultrasound imaging often does not enable reliable selective identification of the most malignant portion of diffuse gliomas (Figure 6). Hence, intraoperative evaluation of the extent of resection of high-grade gliomas may be challenging when only B-mode IOUS is used, because both malignant tumor tissue and peritumoral edema, that is in fact usually a mixture of edema and infiltrating tumor cells (41), are hyperechoic.

A potential technique to differentiate between malignant glioma tissue and peritumoral edema is application of ultrasound contrast agents (42). Despite the fact that contrast-enhanced ultrasound (CEUS) agents, which are composed of small gaseous microbubbles, do not penetrate extravascularly (unlike MRI contrast agents which diffuse into the interstitium through disrupted blood-brain barrier), Prada et al. showed that glioblastoma contrast enhancement with CEUS is superimposable on that provided with preoperative gadolinium-enhanced T1-weighted MRI regarding location, margins, morphologic features, and dimensions, with a similar enhancement pattern (42). Hence, CEUS might play a decisive role in the process of maximizing glioblastoma 


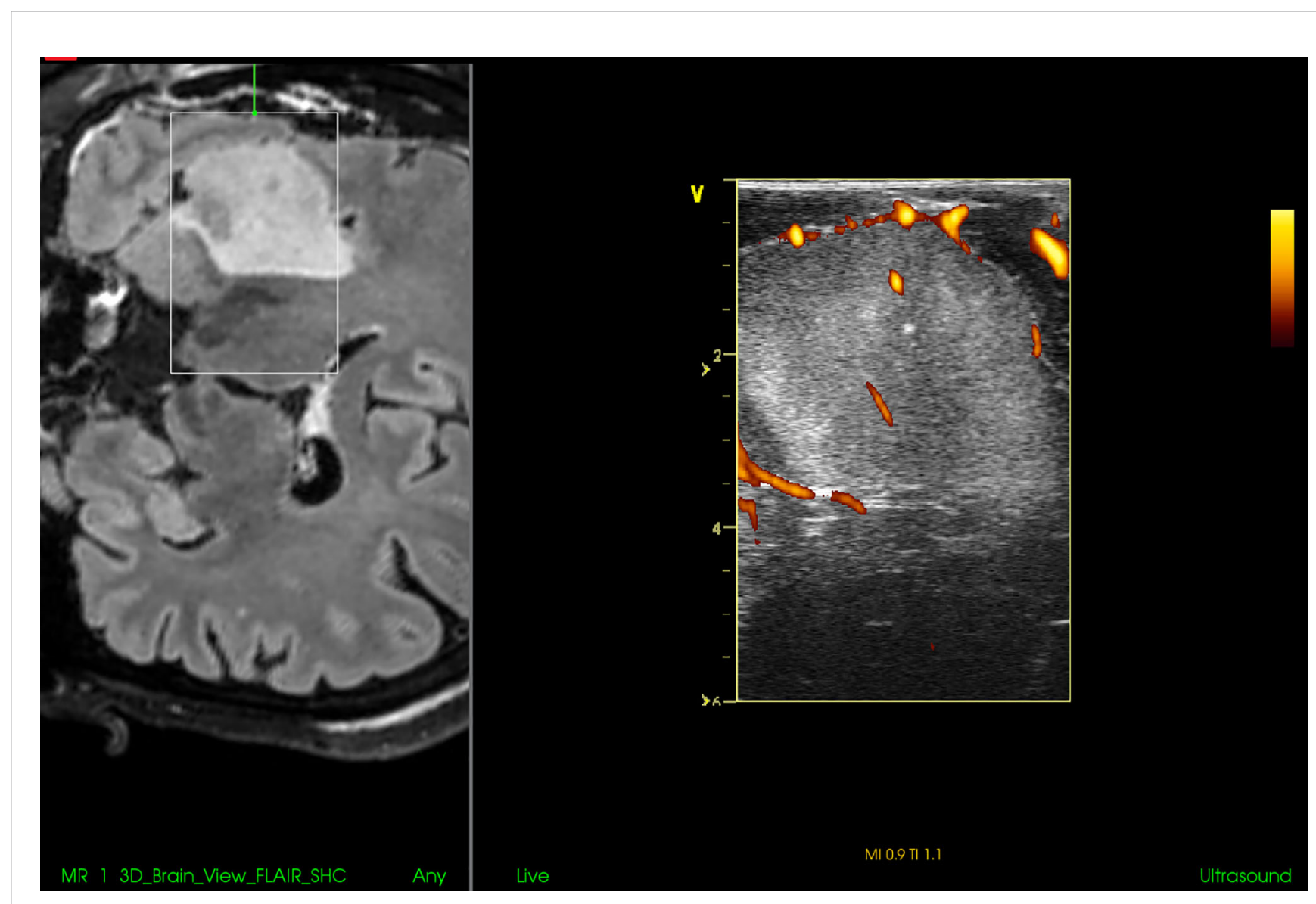

FIGURE 4 | Right-sided insular grade II astrocytoma. Visualization of the tumor before the resection using $12 \mathrm{MHz}$ linear IOUS probe co-registrated with preoperative navigation 3D FLAIR MRI sequence. Note co-registration with navigation MRI facilitates anatomical orientation. 3D, three-dimensional; FLAIR, fluid attenuated inversion recovery; MRI, magnetic resonance imaging; IOUS, intraoperative ultrasound.

resection (43). Of note however, there is currently no commercially available navigated 3D IOUS system supporting CEUS, all IOUS devices enabling CEUS during brain surgeries are $2 \mathrm{D}$.

Another technique to evaluate the extent of high-grade glioma tissue resection is utilization of $\mathrm{B}$-mode IOUS together with 5-aminolevulinic acid (5-ALA) that enables selective malignant tissue visualization (44). In fact, these two methods can be complementary (45), and the combined use of both methods may minimize their pitfalls. Namely, a significant drawback of the intraoperative 5-ALA use is the fact that even a thin layer of intervening low-grade grade tissue is enough to lead to incorrect impression of complete high-grade tumor portion resection (46). Heterogeneous tumors with lowgrade parts sometimes cannot be reliably resected by fluorescence-guided surgery alone, in these cases the additional use of intraoperative imaging is required $(45,47)$. At least in some cases, B-mode IOUS may help to identify larger high-grade glioma residua, and that despite the very challenging differentiation between high-grade tissue and surrounding edema without CEUS (Figure 7). In addition, the fact that some high-grade glioma patients may benefit from further resection of T2 abnormality $(48,49)$ that can be visualized by B-mode ultrasound but not by 5-ALA, underscores the potential benefit of simultaneous use of both methods.

Combination of IOUS and 5-ALA may be potentially useful also when focally malignized low-grade gliomas with no or nonsignificant contrast-enhancement are resected (50). In such cases, 3D IOUS provides adequate visualization of the whole hyperechoic tumor, while the small foci of anaplasia can be intraoperatively identified by 5-ALA fluorescence using the methodology pioneered by Widhalm et al. (51). This approach helps to achieve an extensive resection of glioma tissue and at the same time helps to identify anaplastic foci in order to avoid a sampling error.

\section{ULTRASOUND ARTIFACTS}

Perhaps the most important pitfall of all neurosurgical ultrasound devices is various ultrasound artifacts (52-54). 

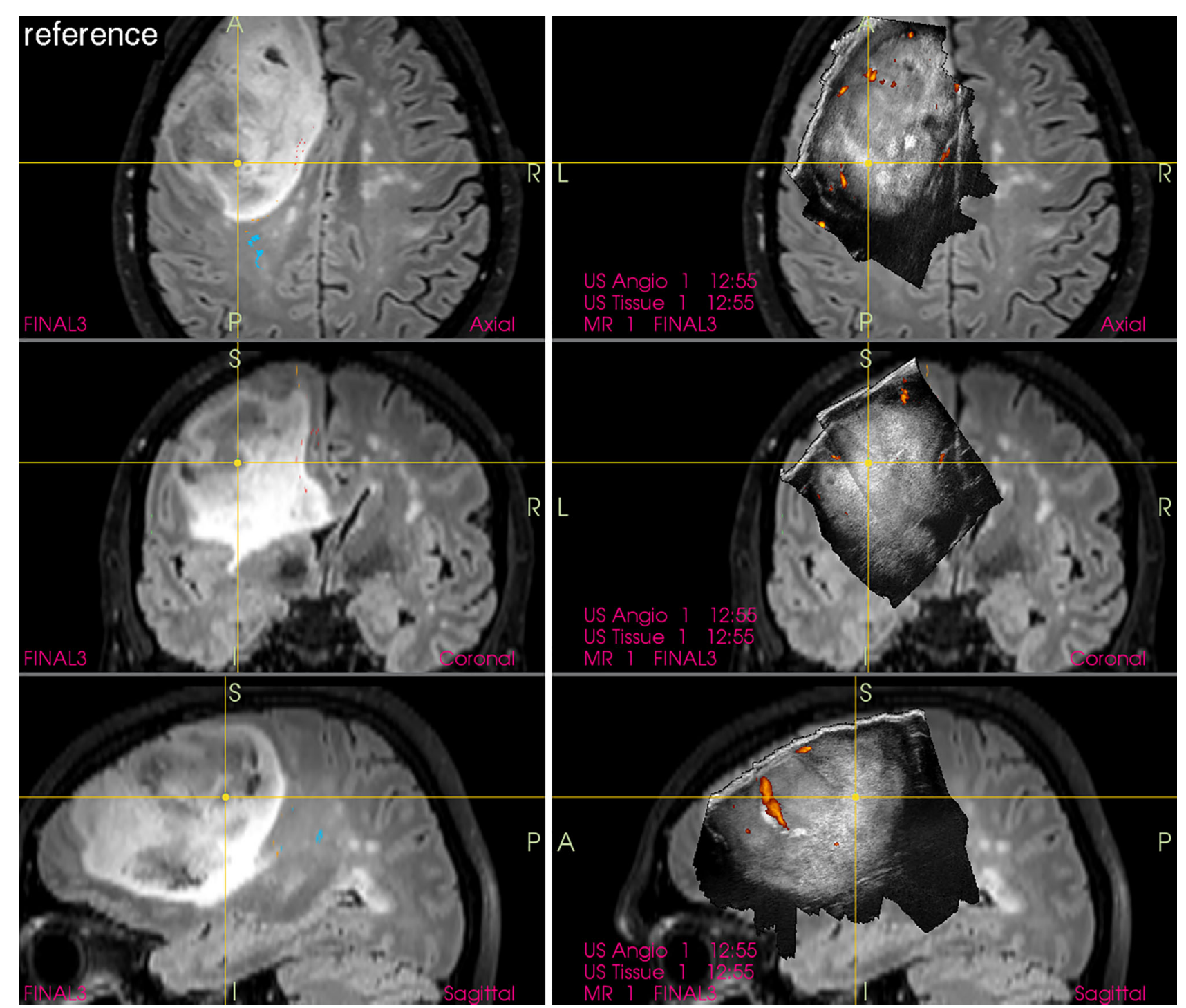

FIGURE 5 | Left-sided frontal grade II astrocytoma (Left column) preoperative navigation 3D FLAIR MRI sequence (3-Tesla MRI scanner) (Right column) preresectional 3D IOUS image fused with navigation FLAIR MRI sequence. Note visualization of the entire tumor on 3D IOUS image despite its large size. 3D, threedimensional; FLAIR, fluid attenuated inversion recovery; MRI, magnetic resonance imaging; IOUS, intraoperative ultrasound.

From practical point of view, the most prominent problem is the acoustic enhancement artifacts (AEAs). These artifacts appear at the bottom of the resection cavity after some tumor debulking $(13,55)$, when ultrasound probe is placed at the level of brain surface and ultrasound waves penetrate through a higher column of saline solution. The appearance of AEAs is due to a large difference between a very low attenuation of acoustic waves in saline solution and high attenuation of acoustic waves in (normal or pathological) tissue $(55,56)$. Because AEAs are, similarly as the majority of brain tumors, hyperechoic, the ultrasonic depiction of medial tumor borders after some tumor debulking may be challenging (53). Acoustic enhancement artifacts are especially significant during resections of voluminous tumors and large resection cavities, as the degree of enhancement depends on the distance that ultrasound waves have traveled in saline. Importantly, AEAs may often preclude the detection of tumor remnants at the bottom of the resection cavity and make IOUS unreliable (Figure 8) (52). Understandably, this happens mostly towards the end of resection, when brain-shift usually occurs and intraoperative imaging is needed most (53).

Several methods that enable differentiation between AEAs and tumor remnants and estimate the extent of resection were presented: The first possibility is to evaluate the bottom of the resection cavity by moving the probe. In realtime 2D IOUS, the location of the AEAs in the image will 


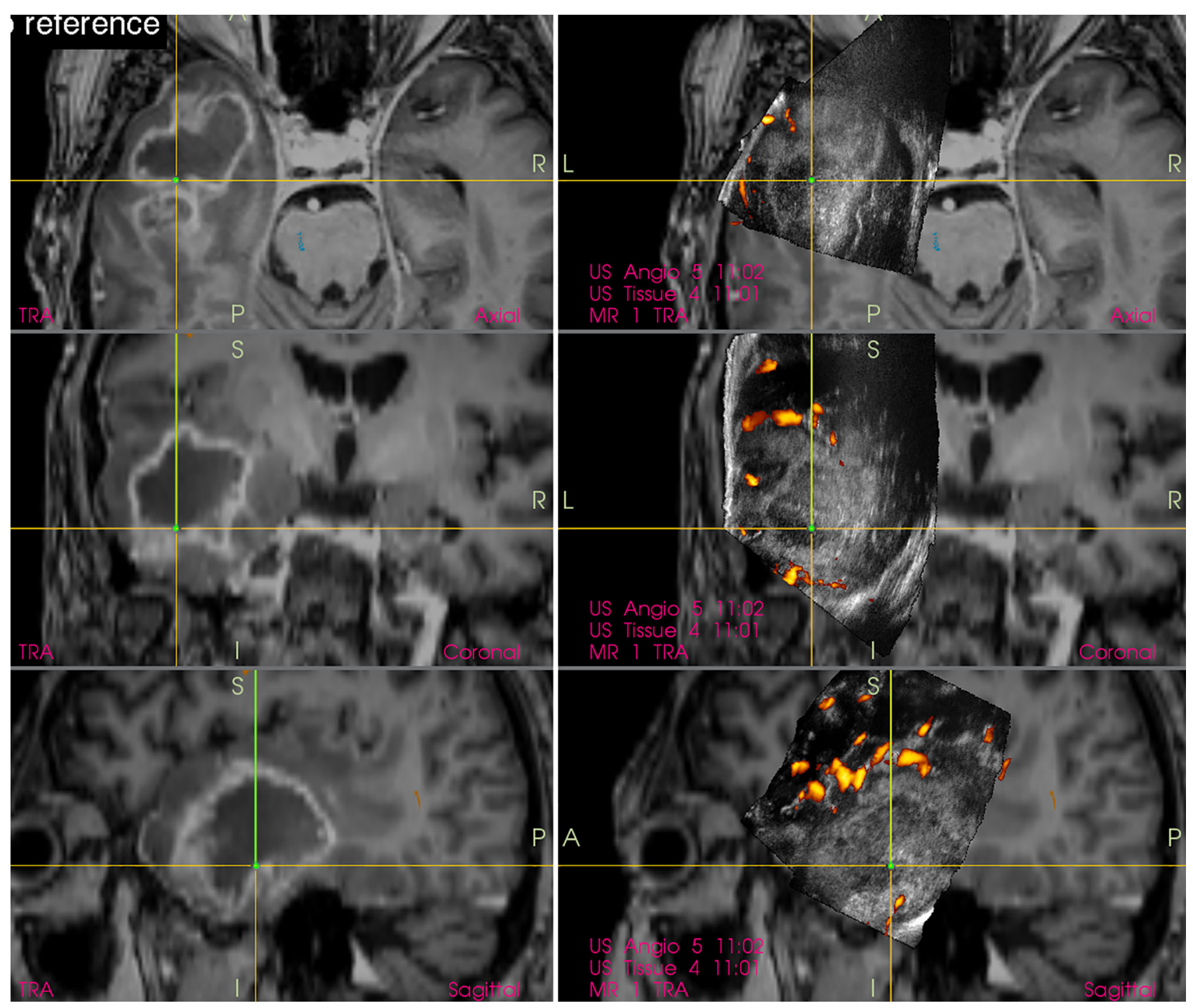

FIGURE 6 | Right-sided temporal glioblastoma (Left column) preoperative navigation 3D contrast-enhanced T1-weighted MRI sequence displaying high-grade tumor showing typical ring enhancement (Right column) pre-resectional 3D IOUS image fused with navigation MRI. Note that the hyperechoic high-grade tumor tissue is not selectively identifiable on the IOUS image, as the surrounding edematous and infiltrated brain (non-enhancing on MRI) is hyperechoic as well. 3D, threedimensional; MRI, magnetic resonance imaging; IOUS, intraoperative ultrasound.

move when the position and angle of ultrasound probe has changed (55).

Another possibility to indirectly distinguish AEAs and residual tumor is a comparison between pre-resectional and updated ultrasound image, performed during or after resection. If the hyperechoic area is localized in a region where no tumor was present before the resection, it is most probably a bright artifact and not a real tumor remnant $(55,57)$.

Thirdly, AEAs may be minimized by inserting a small ultrasound probe into the resection cavity $(13,55,57,58)$. By doing so, the column of saline solution between the tip of the miniature probe and scanned tissue at the bottom of resection cavity is smaller than when scanning with a larger probe placed at the level of the brain surface. Shortening the column of saline solution reduces the AEAs at the bottom of resection cavity, and the structures in the medial part of resection cavity can be distinctly depicted (Figure 9). However, this method is not without limitations. Small probes have a very limited field of view (43), which may be a significant limiting factor predominantly when these probes are used with $2 \mathrm{D}$ IOUS systems (59). Under such circumstances the anatomical orientation may be difficult (43). On the other hand, when used with navigated 3D IUOS, this pitfall may be at least partially minimized, as described by our group (59). Nevertheless, artifacts reduction using mini-probes is certainly not ideal. While frequently allowing depiction of tumor 

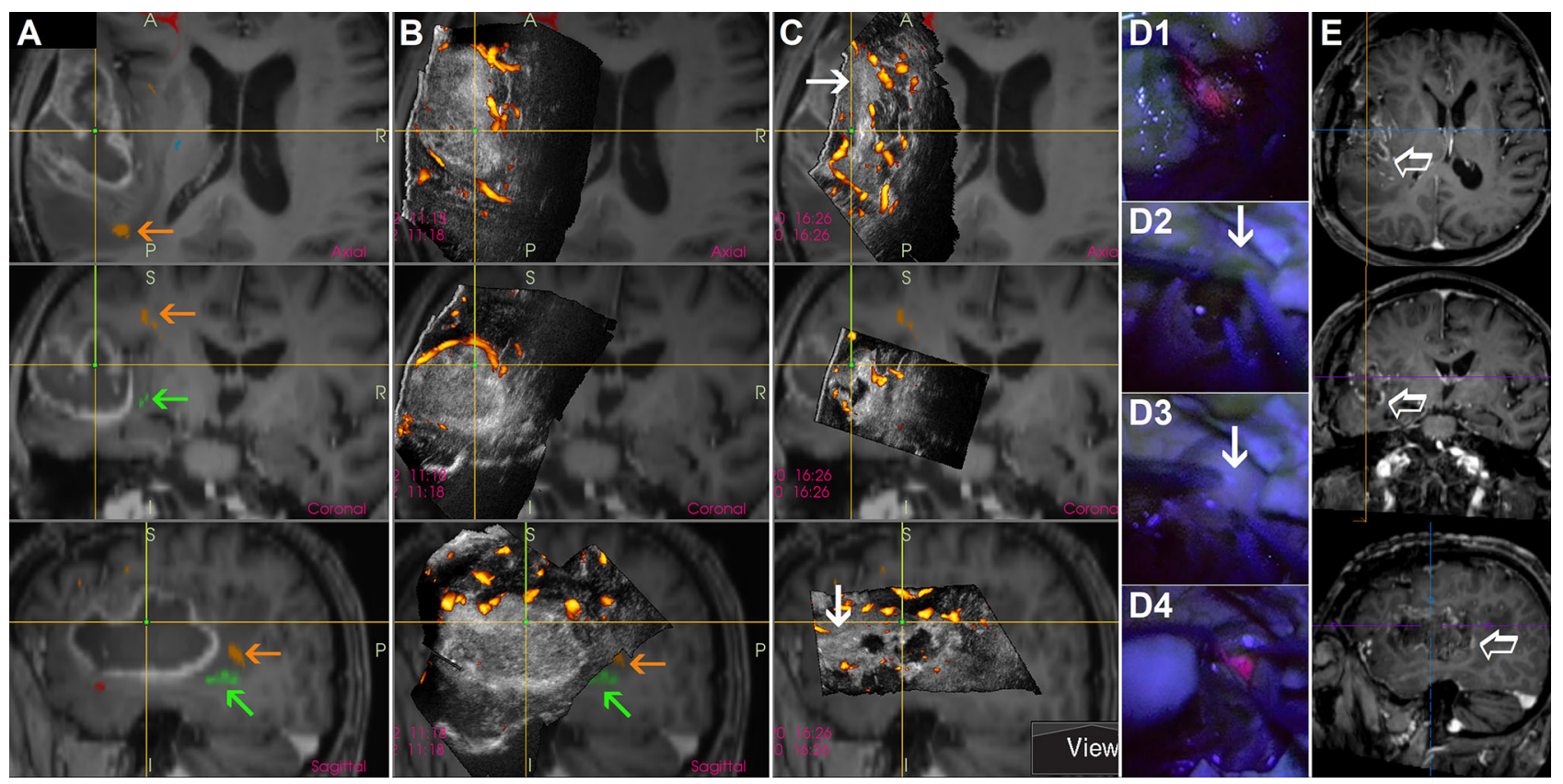

FIGURE 7 | Awake resection of a left-sided temporal glioblastoma guided by direct electrical stimulation, navigated intraoperative 3D IOUS and 5-aminolevulinic acid (A) preoperative navigation 3D contrast-enhanced T1-weighted MRI sequence with implemented tractography. Orange arrows = arcuate fascicle. Green arrows = inferior fronto-occipital fascicle (B) Pre-resectional 3D IOUS image fused with navigation MRI. Orange arrows $=$ arcuate fascicle. Green arrows $=$ inferior frontooccipital fascicle (C) 3D IOUS image acquired during the resection. Despite the absence of red fluorescence in the anterior part of the resection cavity at the time of IOUS scanning, ultrasound image showed a large nodular tumor residuum in this area (arrows) (D1) Distinct red fluorescence observed shortly after the resection beginning (D2, D3) Absence of red fluorescence in the anterior part of the resection cavity. Arrow - presumably high grade tumor part identified using actual 3D IOUS scans (D4) Distinct red fluorescence after cortical resection (E) Postoperative MRI performed 72 hours after the surgery. Empty arrow-contrast-enhancing residual tumor intentionally left in place, electrical stimulation of inferior fronto-occipital fascicle in this area elicited semantic paraphasias. 3D, three-dimensional; MRI, magnetic resonance imaging; IOUS, intraoperative ultrasound.

remnants, it is sometimes problematic to maintain the same distance between the tip of the mini-probe and the resection cavity bottom; when this distance becomes larger AEAs appear (Figure 9). Next, while some linear probes used for intracavitary visualization allow high resolution imaging (17), image quality of other mini-probes is far from ideal. In addition, even small probes may be too bulky to be safely inserted into the resection cavity in between deliberated bridging veins, which may hinder mini-probe insertion (60).

A new solution for this longstanding problem may be minimizing the AEAs by utilizing the artifact reducing acoustic coupling fluid. This fluid was developed by the group of $\mathrm{G}$. Unsgaard $(55,56)$; because the fluid attenuates ultrasound energy similarly to normal brain tissue, the AEAs are minimized. Promising results of phase one clinical study were recently published (61).

\section{CHALLENGING PATIENT POSITIONING}

During scanning the operating field with the ultrasound probe placed at the level of brain surface the resection cavity has to be filled with fluid, most often saline solution (9). If air becomes trapped in the resection cavity, the adequate visualization is compromised. At the interface with structures characterized by very low acoustic impedance (such as entrapped air), the sound will be completely reflected and cannot propagate beyond these interfaces-an "acoustic vacuum" will be created (62). Therefore, the position of the patient's head should enable horizontal position of the craniotomy; in that way fluid will fill a whole resection cavity. However, horizontal placement of the craniotomy may not be optimal in every type of surgery-for example in awake resections of tumors growing close to the Rolandic area and/or supplementary motor area performed in semi-sitting position (which is most comfortable for patients) (Figure 10). In order to keep the fluid within the resection cavity in cases when the craniotomy is not placed horizontally, a miniature barrier made from bone-vax may be effectively used (50) (Figure 11). This "miniature dam" allows sufficient filing of the resection cavity with fluid and appropriate scanning. Another possible solution in cases with non-horizontal placement of the craniotomy is insertion of the hockey stick-shaped ultrasound probe into the resection cavity, as described by Coburger et al. (17). 


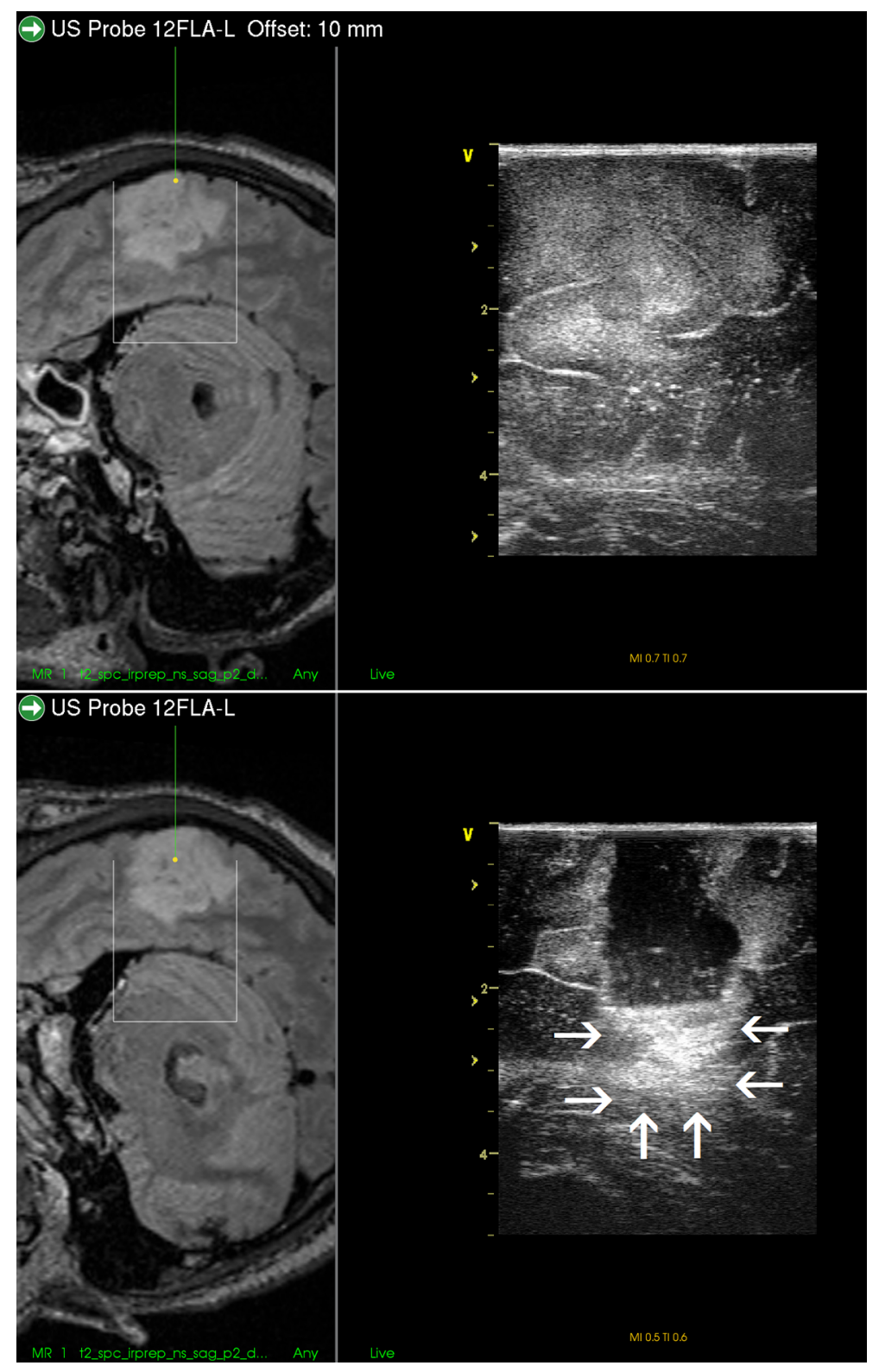

FIGURE 8 | Right-sided temporal grade II oligodendroglioma (Upper row) visualization of the tumor before the resection using $12 \mathrm{MHz}$ linear probe co-registrated with preoperative navigation 3D FLAIR MRI sequence (Lower row) visualization of the tumor after resection of the central tumor part. Note clear visualization of the tumor residua on the sides of the resection cavity, and large acoustic enhancement artifact at the resection cavity-bottom precluding identification of potential tumor remnant in this area. 3D, three-dimensional; FLAIR, fluid attenuated inversion recovery; MRI, magnetic resonance imaging.

\section{ULTRASOUND VISUALIZATION OF SELLAR REGION}

Despite the fact that a variety of IOUS transducers have been applied to transsphenoidal surgery, the significance of endonasal IOUS in the context of transsphenoidal tumor surgeries is still unclear (1). While several reports describe IOUS as a useful adjunct during transsphenoidal resections of microadenomas (63-65) as well of macroadenomas (66-72),
IOUS imaging is generally not considered to be a comparable alternative to intraoperative MRI during resections of sellar tumors (73). There are several pitfalls of IOUS use during trassphenoidal procedures, especially during resections of macroadenomas and giant pituitary adenomas. Firstly, while preoperative imaging of these lesions usually includes coronal T1- and T2-weighted and sagittal T1-weighted MRI scans, as well as coronal and sagittal postcontrast T1-weighted MRI scans (74), only very few reports describe ultrasound imaging 

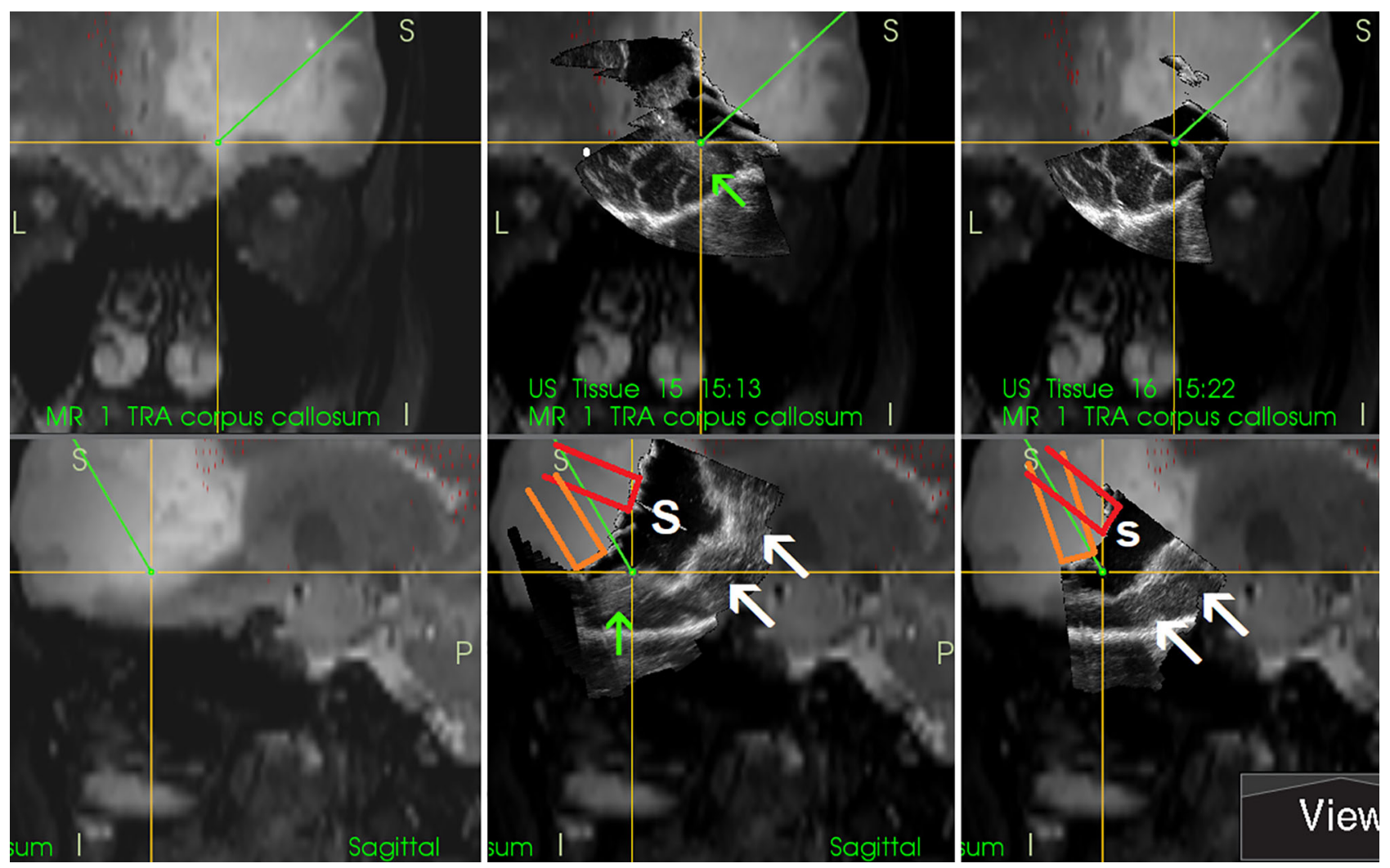

FIGURE 9 | Right-sided frontal grade II oligo-astrocytoma (Left column)-3D T2-weighted navigation sequence (Middle column) 3D IOUS image fused with navigation MRI. The tip of the pointer (green line) points at small tumor residuum (green arrow) visualized by miniprobe inserted into the resection cavity. Red and orange lines: schematic depiction of the miniprobe position within the resection cavity during the scanning. Note that acoustic enhancement artifacts appeared when the distance between the probe-tip and the scanned tissue became larger (arrows) (Right column) The same intraoperative situation as shown in the middle column, 3D IOUS image was acquired after resection of identified tumor residuum. 3D, three-dimensional; MRI, magnetic resonance imaging; IOUS, intraoperative ultrasound; S, hypoechoic saline solution within the resection cavity.

both in sagittal and coronal planes $(66,67)$. On the contrary, numerous IOUS probes used for intraoperative imaging during transsphenoidal procedures offer nonintuitive imaging planes most neurosurgeons are unfamiliar with (69). Secondly, imaging results and interpretation are highly dependent on the skills of the investigator and the resolution of many transducers is low (73). Thirdly-there is currently no commercially available ultrasound device that would enable 3D IOUS reconstructions and image rendering in orthogonal planes, which might improve the surgeon's ability to understand ultrasound imaging of the sellar region (1).

Nevertheless, the available IOUS devices may still offer some important benefits during resections of pituitary tumors. Most importantly, based on the differentiation of the audio signal of a micro-Doppler probe together with neuronavigation, the position of the internal carotid artery within the adenoma-invaded cavernous sinus may be identified and an injury with brisk arterial bleeding can be avoided $(73,75)$. In addition, the position of the carotid artery may be identified also by its visualization using small, side-looking, high-frequency ultrasound probe (68). Next, some IOUS systems enable visualization of suprasellar space, and identification and further resection of residual suprasellar adenoma tissue (Figure 12) (67). This may be of particular importance during resection of giant adenomas, as the suprasellar tumor portion may be unintentionally left in place in spite of endoscope utilization. Identification of unnoticed large suprasellar residua using intraoperative imaging might be crucial to prevent hemorrhagic infarction of the tumor, compression of the hypothalamus and potentially fulminant course $(76,77)$. Lastly, in spite of aforementioned limitations, current IOUS use may contribute to better surgical results as compared to transsphenoidal resections without intraoperative imaging (72).

\section{FUTURE PERSPECTIVES}

Despite the fact that more than four decades have passed since IOUS was initially introduced during a brain tumor resection (6), this intraoperative imaging method still needs substantial improvement to achieve widespread acceptance. Nevertheless, 

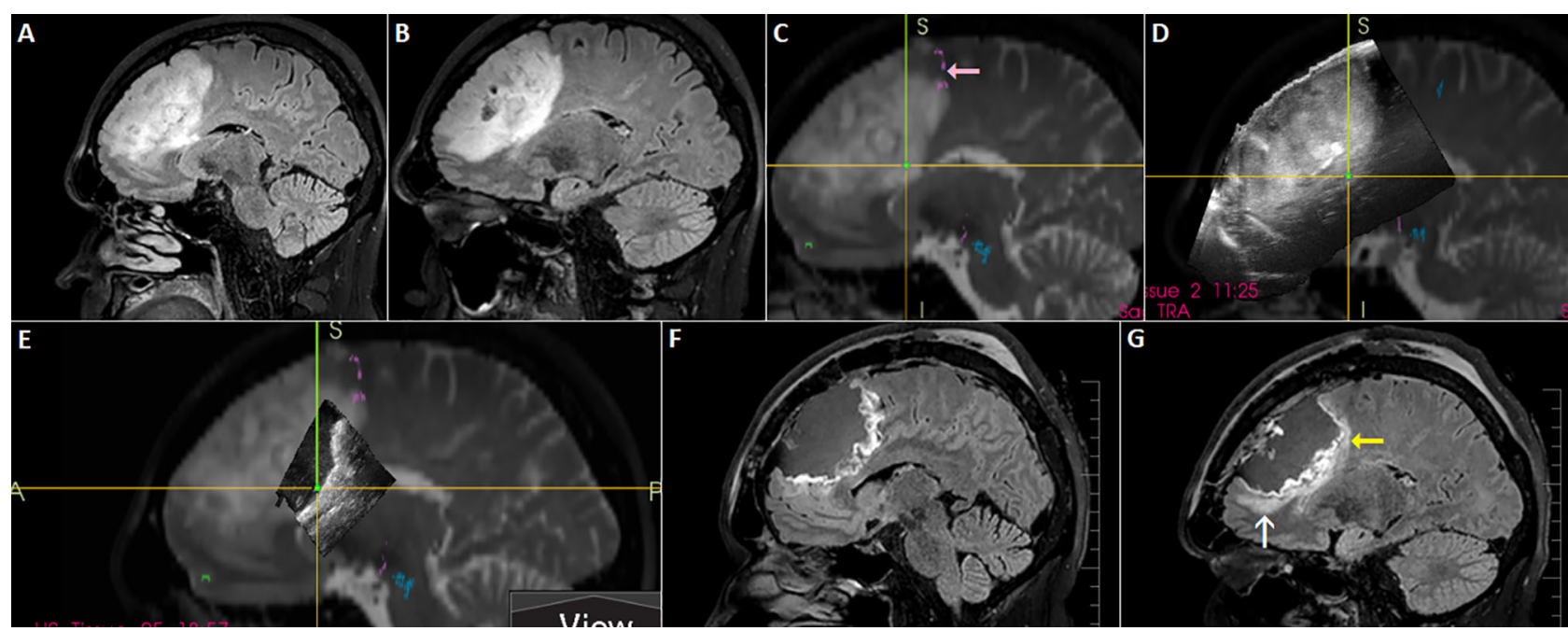

FIGURE 10 | Left-sided frontal oligodendroglioma resected in a semi-sitting position. (A, B) Preoperative sagittal FLAIR MRI sequence (C) 3D T2 sequence fused with tractography. Note involvement of tracts originating in pre-supplemetary motor area (pink arrow) (D) 3D IOUS image fused with navigation MRI (E) Incomplete filling of the resection cavity with saline due to non-horizontal placement of the craniotomy resulted in insufficient scanning of anterior part of the resection cavity (F, G) Postoperative sagittal FLAIR MRI sequence showing resectable residuum (white arrow), as well as residual tumor involving eloquent tracts (yellow arrow). 3D, three-dimensional; FLAIR, fluid attenuated inversion recovery; MRI, magnetic resonance imaging; IOUS, intraoperative ultrasound.

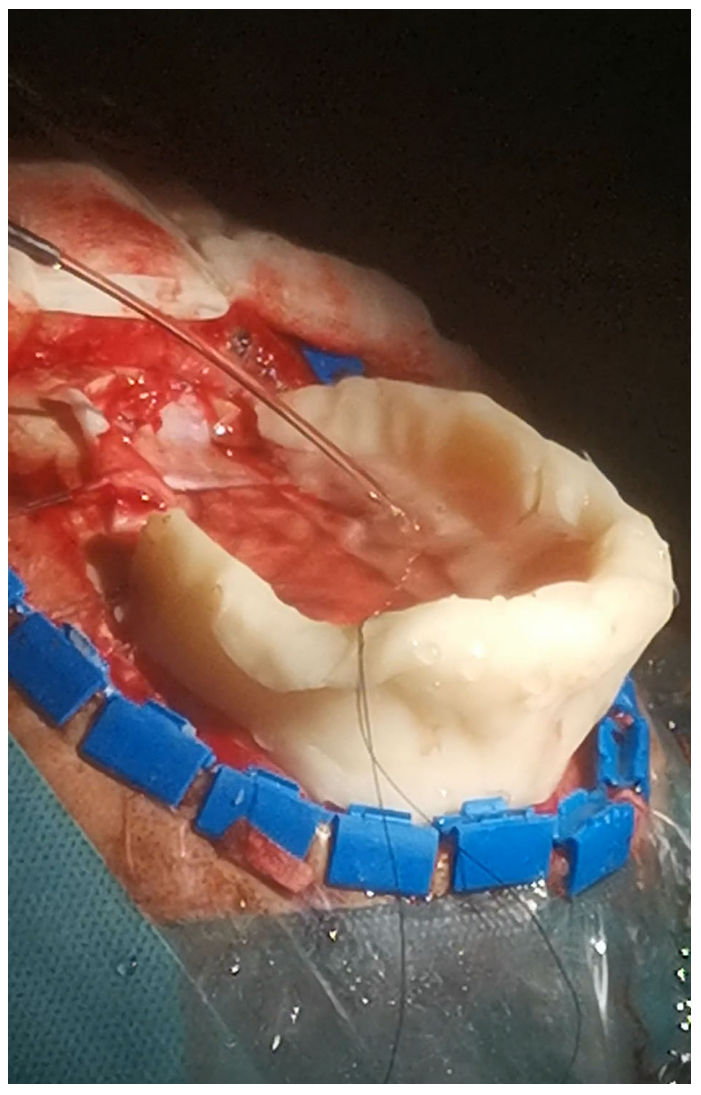

FIGURE 11 | Bone-wax mini-barrier used during removal of a precentral tumor performed in semi-sitting position. the development of neurosurgical IOUS since the beginning of the millennium was substantial, and some pitfalls are close to reasonable solutions. On the contrary, other drawbacks need further development of the neurosurgical IOUS technology.

The prominent problem regarding ultrasound acoustic enhancement artifacts, maybe the biggest drawback of all neurosurgical IOUS devices, might soon be minimized by acoustic coupling fluid mimicking brain tissue.

Introduction of CEUS in order to guide resections of brain tumors made identification and subsequent resection of contrast enhancing malignant glioma tissue much easier. However, an important limitation is the fact that only very few commercially available ultrasound devices dedicated to neurosurgery enable CEUS, and none of them is $3 \mathrm{D}$.

Interpretation of IOUS image during transsphenoidal tumor resections could be significantly easier, if new ultrasound transducers enabling distinct visualization of the sellar region in sagittal and coronal planes were developed, considering the fact that these (and not the oblique) planes are familiar to most pituitary surgeons. Development of new elongated thin ultrasound probes dedicated for intracavitary scanning might be also helpful during identification of residual glioma tissue. The important aspect of the development of new IOUS probes is the achievement of sterile intraoperative working conditions. A neurosurgical IOUS probe can be either sterilized or, if sterilization is not possible, covered with sterile sheath containing sterile coupling gel (1). Sterilization protocols of IOUS probes that contact brain tissue and cerebrospinal fluid must strictly respect regional regulations. If sterile covers are used, they should be fit tightly to the probe (1) in order to minimize the artifacts and to not alter the (special) probe shape and/or significantly enlarge the actual probe volume. 


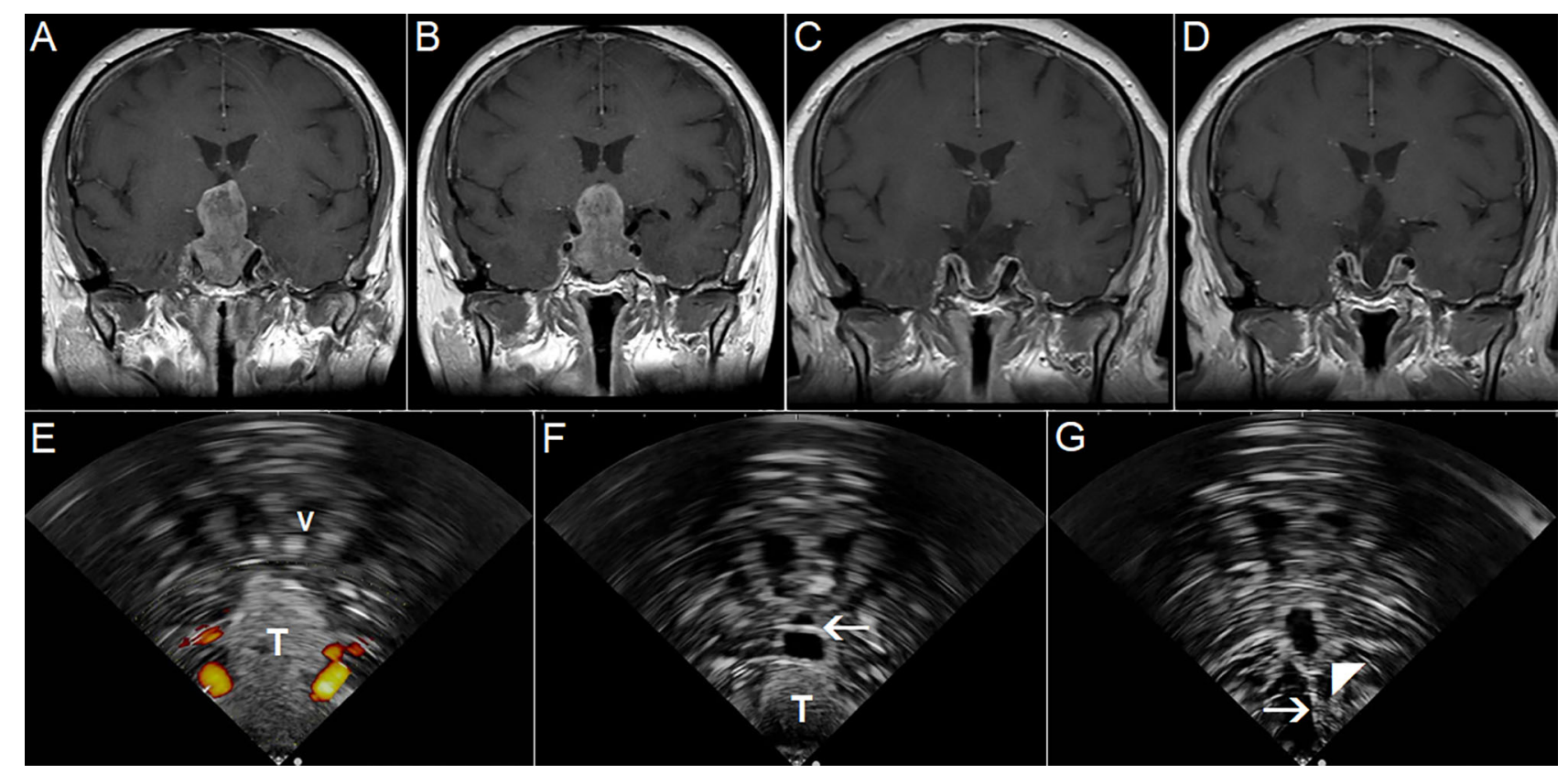

FIGURE 12 | Pituitary macroadenoma invading left cavernous sinus (A, B) Preoperative coronal contrast-enhanced T1 MRI sequence (C, D) Postoperative coronal contrast-enhanced T1 MRI sequence, small tumor residuum was intentionally left in the left cavernous sinus (E) Pre-resectional 2D IOUS image using flexible miniprobe, note distinct depiction of the tumor tissue as well as visualization of upper segments of carotid arteries by power-Doppler mode (F) Intraoperative 2D IOUS image after partial tumor resection. Note partial decompression of the third ventricle with depicted interthalamic adhesion (arrow) (G) 2D IOUS image after tumor resection, note pituitary stalk is distinctly visible (arrow) as well as the floor of the 3rd ventricle (arrowhead). 2D, two-dimensional; MRI, magnetic resonance imaging; IOUS, intraoperative ultrasound; V, lateral ventricle; T, tumor.

Introduction of navigated 3D IOUS reduced anatomical orientation problems caused by nonintuitive oblique planes during many types of brain surgeries by rendering IOUS images in orthogonal planes. Nevertheless, only a few studies examining effectiveness of navigated 3D IOUS utilization during transsphenoidal surgeries and CEUS-guided brain tumor resections were reported $(78,79)$. Research in this area should continue and result into commercially available navigated 3D IOUS systems enabling both aforementioned types of intraoperative imaging.

Correct positioning of patients before IOUS-guided resections in order to allow sufficient filling of resection cavity with fluid may be challenging; utilization of alternative adjuncts such as minibarriers may be required. However, it is necessary to emphasize that patient positioning during intraoperative MRI-guided surgeries on the MRI table is sometimes also less-than-ideal, especially during awake tumor resections (80). Regarding awake procedures, it is worth noting that IOUS is a less time-consuming imaging modality than intraoperative MRI (50). This might be an important factor during procedures performed in conscious patients, as awake tumor resections have limited duration due to patient fatigue (81). Comparative studies examining effectiveness of both imaging modalities during awake resections should be conducted.

Traditional perception of intraoperative ultrasound as a modality with low image quality is slowly being overcome by innovation of ultrasound devices and ultrasound transducers.
New high frequency IOUS probes may have strikingly highresolution image. Visualization of tiny perforating arteries using power-Doppler mode seems to be at least comparable to MRI devices (Figure 13) (22).

Of note, as IOUS is strongly investigator-dependent, sufficient knowledge on ultrasound imaging of normal and pathological brain structures, as well as proper training are crucial for successful course of IOUS-guided resections (82). Recent IOUS simulation methods e.g. "virtual probes" (82) or IOUSsimulation smartphone applications (82), and practice on phantom (83) or animal (84) models under supervision of expert sonographers are recommended in order to refine scanning and surgical techniques (1). As showed recently by group of DiMeco, current high-end 2D IOUS systems integrated with neuronavigation may be in experienced hands of a significant benefit in terms of both extent of brain tumor resections and neurological outcomes (85). However, further prospective studies are necessary to evaluate impact of IOUS on surgical results $(86,87)$.

Lastly, algorithms allowing brain shift compensation based on preoperative MRI-to-IOUS rigid registration were already presented and their effectiveness was evaluated both during and after surgical procedures (88). While the rigid registration improved the alignment of the MRI and IOUS image volumes, considering the fact that brain-shift is a nonlinear process, deformable registration has the potential to further improve the results (88). Future sophisticated fusion algorithms 

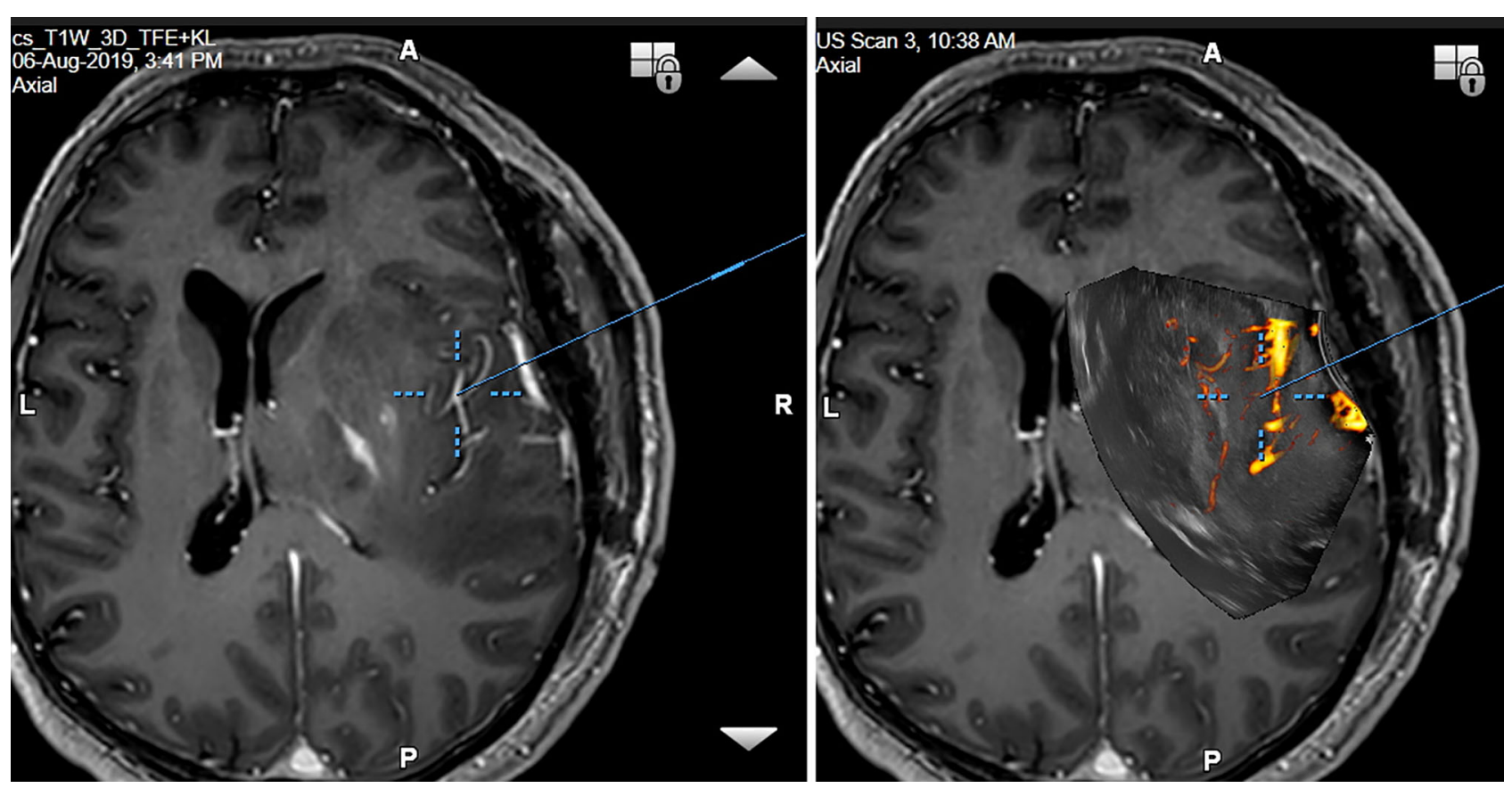

FIGURE 13 | Right-sided temporo-insular glioma (reoperation after previous urgent brainstem decompression) (Left column) preoperative navigation 3D contrastenhanced T1-weighted MRI sequence (3-Tesla MRI scanner) (Right column) pre-resectional 3D IOUS image fused with navigation MRI using a high-end navigated 3D IOUS system. Note the excellent visualization of perforating lenticulostriate arteries under the infiltrated right insula. 3D, three-dimensional; MRI, magnetic resonance imaging; IOUS, intraoperative ultrasound.

might use IOUS image as anatomical reference, similarly to intraoperative $\mathrm{CT}$, and enable deformation of preoperative $3 \mathrm{D}$ MRI image into "virtual intraoperative MRI" (89).

\section{AUTHOR CONTRIBUTIONS}

A $\breve{S}$-manuscript writing, figure development, literature review, and data acquisition. JB - data acquisition and manuscript editing and review. $\mathrm{VB}-$ data acquisition and manuscript editing and review. AK-data acquisition and manuscript editing and

\section{REFERENCES}

1. Sastry R, Bi WL, Pieper S, Frisken S, Kapur T, Wells W3rd, et al. Applications of Ultrasound in the Resection of Brain Tumors. J Neuroimaging (2017) 27 (1):5-15. doi: 10.1111/jon.12382

2. Dasenbrock HH, See AP, Smalley RJ, Bi WL, Dolati P, Frerichs KU, et al. Frameless Stereotactic Navigation during Insular Glioma Resection using Fusion of Three-Dimensional Rotational Angiography and Magnetic Resonance Imaging. World Neurosurg (2019) 126:322-30. doi: 10.1016/ j.wneu.2019.03.096

3. Gerard IJ, Kersten-Oertel M, Petrecca K, Sirhan D, Hall JA, Collins LC. Brain shift in neuronavigation of brain tumors. A review. Med Image Anal (2017) 35:403-20. doi: 10.1016/j.media.2016.08.007

4. Nimsky C. Intraoperative MRI in glioma surgery: proof of benefit? Lancet Oncol (2011) 12(11):982-3. doi: 10.1016/S1470-2045(11)70219-4

5. Nimsky C, Ganslandt O, Cerny S, Hastreiter P, Greiner G, Fahlbusch R. Quantification of, visualization of, and compensation for brain shift using review. DT - data acquisition and manuscript editing and review. $\mathrm{AL}$ - data acquisition and manuscript editing and review. All authors contributed to the article and approved the submitted version.

\section{FUNDING}

This work was supported by the Scientific grant agency of the Ministry of education of the Slovak republic and the Slovak academy of sciences (VEGA) in the form of grant (number $1 /$ $0719 / 18)$

intraoperative magnetic resonance imaging. Neurosurgery (2000) 47:1070-80. doi: 10.1097/00006123-200011000-00008

6. Rubin JM, Mirfakhraee M, Duda EE, Dohrmann GJ, Brown F. Intraoperative ultrasound examination of the brain. Radiology (1980) 137(3):831-2. doi: 10.1148/radiology.137.3.6255514

7. Unsgaard G, Gronningsaeter A, Ommedal S, Nagelhus Hernes TA. Brain operations guided by real-time two-dimensional ultrasound: new possibilities as a result of improved image quality. Neurosurgery (2002) 51(2):402-11. doi: 10.1227/01.NEU.0000019873.66709.0D

8. Unsgaard G, Rygh OM, Selbekk T, Müller TB, Kolstad F, Lindseth F, et al. Intra-operative 3D ultrasound in neurosurgery. Acta Neurochir (2006) 148 (3):235-53. doi: 10.1007/s00701-005-0688-y

9. Unsgård G, Solheim $O$, Lindseth F, Selbekk T. Intra-operative imaging with 3D ultrasound in neurosurgery. Acta Neurochir Suppl (2011) 109:181-6. doi: 10.1007/978-3-211-99651-5_28

10. Mair R, Heald J, Poeata I, Ivanov M. A practical grading system of ultrasonographic visibility for intracerebral lesions. Acta Neurochir (2013) 155(12):2293-8. doi: 10.1007/s00701-013-1868-9 
11. Velthoven VV. Intraoperative ultrasound imaging: comparison of pathomorphological findings in US versus CT, MRI and intraoperative findings. Acta Neurochir Suppl (2003) 85:95-9. doi: 10.1007/978-3-70916043-5_13

12. Unsgaard G, Selbekk T, Brostrup Müller T, Ommedal S, Torp SH, Myhr G, et al. Ability of navigated 3D ultrasound to delineate gliomas and metastasescomparison of image interpretations with histopathology. Acta Neurochir (2005) 147(12):1259-69. doi: 10.1007/s00701-005-0624-1

13. Šteňo A, Karlík M, Mendel P, Č́́k M, Šteňo J. Navigated three-dimensional intraoperative ultrasound-guided awake resection of low-grade glioma partially infiltrating optic radiation. Acta Neurochir (2012) 154(7):1255-62. doi: 10.1007/s00701-012-1357-6

14. Moiyadi AV, Shetty PM, Mahajan A, Udare A, Sridhar E. Usefulness of threedimensional navigable intraoperative ultrasound in resection of brain tumors with a special emphasis on malignant gliomas. Acta Neurochir (2013) 155 (12):2217-25. doi: 10.1007/s00701-013-1881-z

15. Solheim $O$, Selbekk $T$, Lindseth F, Unsgård G. Navigated resection of giant intracranial meningiomas based on intraoperative 3D ultrasound. Acta Neurochir (2009) 151(9):1143-51. doi: 10.1007/s00701-009-0395-1

16. Solheim O, Selbekk T, Jakola AS, Unsgård G. Ultrasound-guided operations in unselected high-grade gliomas-overall results, impact of image quality and patient selection. Acta Neurochir (2010) 152(11):1873-86. doi: 10.1007/ s00701-010-0731-5

17. Coburger J, Scheuerle A, Thal DR, Engelke J, Hlavac M, Wirtz CHR, et al. Linear array ultrasound in low-grade glioma surgery: histology-based assessment of accuracy in comparison to conventional intraoperative ultrasound and intraoperative MRI. Acta Neurochir (2015) 157(2):195-206. doi: 10.1007/s00701-014-2314-3

18. Ravn Munkvold BK, Bø HK, Jakola AS, Reinertsen I, Berntsen EM, Unsgård G, et al. Tumor Volume Assessment in Low-Grade Gliomas: A Comparison of Preoperative Magnetic Resonance Imaging to Coregistered Intraoperative 3Dimensional Ultrasound Recordings. Neurosurgery (2018) 83(2):288-96. doi: 10.1093/neuros/nyx392

19. Ravn Munkvold BK, Jakola AS, Reinertsen I, Sagberg LM, Unsgård G, Solheim O. The Diagnostic Properties of Intraoperative Ultrasound in Glioma Surgery and Factors Associated with Gross Total Tumor Resection. World Neurosurg (2018) 115:e129-36. doi: 10.1016/j.wneu.2018.03.208

20. Duffau H. A personal consecutive series of surgically treated 51 cases of insular WHO Grade II glioma: advances and limitations. J Neurosurg (2009) 110:696708. doi: 10.3171/2008.8.JNS08741

21. Jakola AS, Berntsen EM, Christensen P, Gulati S, Unsgård G, Kvistad KA, et al. Surgically acquired deficits and diffusion weighted MRI changes after glioma resection-a matched case-control study with blinded neuroradiological assessment. PLoS One (2014) 9:e101805. doi: 10.1371/ journal.pone. 0101805

22. Šteňo A, Jezberová M, Hollý V, Timárová G, Šteňo J. Visualization of lenticulostriate arteries during insular low-grade glioma surgeries by navigated 3D ultrasound power Doppler: technical note. J Neurosurg (2016) 125(4):1016-23. doi: 10.3171/2015.10.JNS151907

23. Prada F, Del Bene M, Moiraghi A, DiMeco F. "Echographic brain semeiology and topographic anatomy according to surgical approaches". In: F Prada, L Solbiati, A Martegani, F DiMeco, editors. Intraoperative Ultrasound (IOUS) in Neurosurgery: From Standard B-Mode to Elastosonography. Cham: Springer International Publishing (2016). p. 29-39.

24. Bozinov O, Burkhardt JK, Fischer CM, Kockro RA, Bernays RL, Bertalanffy H. Advantages and limitations of intraoperative 3D ultrasound in neurosurgery. Technical note. Acta Neurochir Suppl (2011) 109:191-6. doi: 10.1007/978-3211-99651-5_30

25. Unsgaard G, Ommedal S, Muller T, Gronningsaeter A, Nagelhus Hernes TA. Neuronavigation by intraoperative three-dimensional ultrasound: initial experience during brain tumor resection. Neurosurgery (2002) 50(4):804-12. doi: 10.1097/00006123-200204000-00022

26. Wirtz CR, Albert FK, Schwaderer M, Heuer C, Staubert A, Tronnier VM, et al. The benefit of neuronavigation for neurosurgery analyzed by its impact on glioblastoma surgery. Neurol Res (2000) 22(4):354-60. doi: 10.1080/ 01616412.2000.11740684

27. Kurimoto M, Hayashi N, Kamiyama H, Nagai S, Shibata T, Asahi T, et al. Impact of neuronavigation and image-guided extensive resection for adult patients with supratentorial malignant astrocytomas: a single-institution retrospective study. Minim Invasive Neurosurg (2004) 47(5):278-83. doi: 10.1055/s-2004-830093

28. Bello L, Gallucci M, Fava M, Carrabba G, Giussani C, Acerbi F, et al. i Intraoperative subcortical language tract mapping guides surgical removal of gliomas involving speech areas. Neurosurgery (2007) 60(1):67-80. doi: 10.1227/01.NEU.0000249206.58601.DE

29. Mert A, Kiesel B, Wöhrer A, Martínez-Moreno M, Minchev G, Furtner J. at al. Introduction of a standardized multimodality image protocol for navigationguided surgery of suspected low-grade gliomas. Neurosurg Focus (2015) 38(1): E4. doi: 10.3171/2014.10.FOCUS14597

30. Pinsker MO, Nabavi A, Mehdorn HM. Neuronavigation and resection of lesions located in eloquent brain areas under local anesthesia and neuropsychological-neurophysiological monitoring. Minim Invasive Neurosurg (2007) 50(5):281-4. doi: 10.1055/s-2007-985825

31. Chang EF, Smith JS, Chang SM, Lamborn KR, Prados MD, Butowski N, et al. Preoperative prognostic classification system for hemispheric low-grade gliomas in adults. J Neurosurg (2008) 109(5):817-24. doi: 10.3171/JNS/ 2008/109/11/0817

32. Senft C, Bink A, Franz K, Vatter H, Gasser T, Seifert V. Intraoperative MRI guidance and extent of resection in glioma surgery: a randomised, controlled trial. Lancet Oncol (2011) 12(11):997-1003. doi: 10.1016/S1470-2045(11) 70196-6

33. Gronningsaeter A, Kleven A, Ommedal S, Aarseth TE, Lie T, Lindseth F, et al. SonoWand, an ultrasound-based neuronavigation system. Neurosurgery (2000) 47(6):1373-9. doi: 10.1097/00006123-200012000-00021

34. Hata N, Dohi T, Iseki H, Takakura K. Development of a frameless and armless stereotactic neuronavigation system with ultrasonographic registration. Neurosurgery (1997) 41(3):608-13. doi: 10.1097/00006123-199709000-00020

35. Koivukangas J, Louhisalmi Y, Alakuijala J, Oikarinen J. Ultrasound-controlled neuronavigator-guided brain surgery. J Neurosurg (1993) 79(1):36-42. doi: 10.3171/jns.1993.79.1.0036

36. Trobaugh JW, Richard WD, Smith KR, Bucholz RD. Frameless stereotactic ultrasonography: method and applications. Comput Med Imaging Graph (1994) 18(4):235-46. doi: 10.1016/0895-6111(94)90048-5

37. Moiyadi AV, Unsgård G. "Navigable ultrasound, 3D ultrasound and fusion imaging in neurosurgery". In: F Prada, L Solbiati, A Martegani, F DiMeco, editors. Intraoperative Ultrasound (IOUS) in Neurosurgery: From Standard BMode to Elastosonography. Cham: Springer International Publishing (2016). p. $135-45$.

38. Lindseth F, Kaspersen JH, Ommedal S, Langø T, Bang J, Hokland J, et al. Multimodal image fusion in ultrasound-based neuronavigation: improving overview and interpretation by integrating preoperative MRI with intraoperative 3D ultrasound. Comput Aided Surg (2003) 8(2):49-69. doi: 10.3109/10929080309146040

39. Patil AD, Singh V, Sukumar V, Shetty PM, Moiyadi AV. Comparison of outcomes of free-hand 2-dimensional ultrasound-guided versus navigated 3dimensional ultrasound-guided biopsy for supratentorial tumours: a singleinstitution experience with 125 cases. Ultrasonography (2019) 38(3):255-63. doi: $10.14366 /$ usg. 18036

40. Sanai N, Polley MY, McDermott MW, Parsa AT, Berger MS. An extent of resection threshold for newly diagnosed glioblastomas. J Neurosurg (2011) 115 (1):3-8. doi: 10.3171/2011.2.jns10998

41. Kotrotsou A, Elakkad A, Sun J, Thomas GA, Yang D, Abrol S, et al. Multicenter study finds postoperative residual non-enhancing component of glioblastoma as a new determinant of patient outcome. J Neurooncol (2018) 139(1):125-33. doi: 10.1007/s11060-018-2850-4

42. Prada F, Vitale V, Del Bene M, Boffano C, Sconfienza LM, Pinzi V, et al. Contrast-enhanced MR Imaging versus Contrast-enhanced US: A Comparison in Glioblastoma Surgery by Using Intraoperative Fusion Imaging. Radiology (2017) 285(1):242-9. doi: 10.1148/radiol.2017161206

43. Prada F, Del Bene M, Fornaro R, Vetrano IG, Martegani A, Aiani L, et al. Identification of residual tumor with intraoperative contrast-enhanced ultrasound during glioblastoma resection. Neurosurg Focus (2016) 40(3):E7. doi: 10.3171/2015.11.FOCUS15573

44. Stummer W, Pichlmeier U, Meinel T, Wiestler OD, Zanella F, Reulen HJ. ALA-Glioma Study Group Fluorescence-guided surgery with 5aminolevulinic acid for resection of malignant glioma: a randomised 
controlled multicentre phase III trial. Lancet Oncol (2006) 7(5):392-401. doi: 10.1016/S1470-2045(06)70665-9

45. Moiyadi A, Shetty P. Navigable intraoperative ultrasound and fluorescenceguided resections are complementary in resection control of malignant gliomas: one size does not fit all. J Neurol Surg A Cent Eur Neurosurg (2014) 75(6):434-41. doi: 10.1055/s-0034-1372436

46. Eyüpoglu IY, Hore N, Savaskan NE, Grummich P, Roessler K, Buchfelder M, et al. Improving the extent of malignant glioma resection by dual intraoperative visualization approach. PLoS One (2012) 7(9):e44885. doi: 10.1371/journal.pone.0044885

47. Tsugu A, Ishizaka H, Mizokami Y, Osada T, Baba T, Yoshiyama M, et al. Impact of the combination of 5-aminolevulinic acid-induced fluorescence with intraoperative magnetic resonance imaging-guided surgery for glioma. World Neurosurg (2011) 76(1-2):120-7. doi: 10.1016/j.wneu.2011.02.005

48. Beiko J, Suki D, Hess KR, Fox BD, Cheung V, Cabral M, et al. IDH1 mutant malignant astrocytomas are more amenable to surgical resection and have a survival benefit associated with maximal surgical resection. Neuro Oncol (2014) 16(1):81-91. doi: 10.1093/neuonc/not159

49. Li YM, Suki D, Hess K, Sawaya R. The influence of maximum safe resection of glioblastoma on survival in 1229 patients: Can we do better than gross-total resection? J Neurosurg (2016) 124(4):977-88. doi: 10.3171/2015.5.JNS142087

50. Šteňo A, Giussani C, Riva M. "Multimodal imaging in glioma surgery". In: F Prada, L Solbiati, A Martegani, F DiMeco, editors. Intraoperative Ultrasound (IOUS) in Neurosurgery: From Standard B-Mode to Elastosonography. Cham: Springer International Publishing (2016). p. 81-97.

51. Widhalm G, Wolfsberger S, Minchev G, Woehrer A, Krssak M, Czech T, et al. 5-Aminolevulinic acid is a promising marker for detection of anaplastic foci in diffusely infiltrating gliomas with nonsignificant contrast enhancement. Cancer (2010) 116(6):1545-52. doi: 10.1002/cncr.24903

52. Petridis AK, Anokhin M, Vavruska J, Mahvash M, Scholz M. The value of intraoperative sonography in low grade glioma surgery. Clin Neurol Neurosurg (2015) 131:64-8. doi: 10.1016/j.clineuro.2015.02.004

53. Hentschel SJ, Lang FF. Surgical resection of intrinsic insular tumors. Neurosurgery (2005) 57(1 Suppl):176-83. doi: 10.1227/01.neu.0000163603. 70972.ab

54. Gerganov VM, Samii A, Giordano M, Samii M, Fahlbusch R. Twodimensional high-end ultrasound imaging compared to intraoperative MRI during resection of low-grade gliomas. J Clin Neurosci (2011) 18(5):669-73. doi: $10.1016 /$ j.jocn.2010.08.017

55. Selbekk T, Jakola AS, Solheim O, Johansen TF, Lindseth F, Reinertsen I, et al. Ultrasound imaging in neurosurgery: approaches to minimize surgically induced image artefacts for improved resection control. Acta Neurochir (2013) 155:973-80. doi: 10.1007/s00701-013-1647-7

56. Jakola AS, Jørgensen A, Selbekk T, Michler RP, Solheim O, Torp SH, et al. Animal study assessing safety of an acoustic coupling fluid that holds the potential to avoid surgically induced artifacts in 3D ultrasound guided operations. BMC Med Imaging (2014) 14:11. doi: 10.1186/1471-2342-14-11

57. Steno A, Matejcik V, Steno J. Intraoperative ultrasound in low-grade glioma surgery. Clin Neurol Neurosurg (2015) 135:96-9. doi: 10.1016/ j.clineuro.2015.05.012

58. Coburger J, Konig RW, Scheuerle A, Engelke J, Hlavac M, Thal DR, et al. Navigated high frequency ultrasound: description of technique and clinical comparison with conventional intracranial ultrasound. World Neurosurg (2014) 82:366-75. doi: 10.1016/j.wneu.2014.05.025

59. Steno A, Matejcik V, Steno J. Letter to the editor: identification of residual glioma using ultrasound miniprobes. Neurosurg Focus (2016) 41:E15. doi: 10.3171/2016.5.FOCUS16180

60. Šteňo A, Hollý V, Mendel P, Šteňová V, Petričková Ľ, Timárová G, et al. Navigated 3D-ultrasound versus conventional neuronavigation during awake resections of eloquent low-grade gliomas: a comparative study at a single institution. Acta Neurochir (2018) 160(2):331-42. doi: 10.1007/s00701-0173377-8

61. Unsgård G, Sagberg LM, Müller S, Selbekk T. A new acoustic coupling fluid with ability to reduce ultrasound imaging artefacts in brain tumour surgery-a phase I study. Acta Neurochir (2019) 161(7):1475-86. doi: 10.1007/s00701019-03945-x

62. Martegani A, Mattei L, Aiani L. "US Physics, Basic Principles, and Clinical Application“. In: F Prada, L Solbiati, A Martegani, F DiMeco, editors.
Intraoperative Ultrasound (IOUS) in Neurosurgery: From Standard B-Mode to Elastosonography. Cham: Springer International Publishing (2016). p. 9-17.

63. Ram Z, Shawker TH, Bradford MH, Doppman JL, Oldfield EH. Intraoperative ultrasound-directed resection of pituitary tumors. J Neurosurg (1995) 83 (2):225-30. doi: 10.3171/jns.1995.83.2.0225

64. Watson JC, Shawker TH, Nieman LK, DeVroom HL, Doppman JL, Oldfield $\mathrm{EH}$. Localization of pituitary adenomas by using intraoperative ultrasound in patients with Cushing's disease and no demonstrable pituitary tumor on magnetic resonance imaging. J Neurosurg (1998) 89(6):927-32. doi: 10.3171/ jns.1998.89.6.0927

65. Knappe UJ, Engelbach M, Konz K, Lakomek HJ, Saeger W, Schönmayr R, et al. Ultrasound-assisted microsurgery for Cushing's disease. Exp Clin Endocrinol Diabetes (2011) 119(4):191-200. doi: 10.1055/s-0029-1241207

66. Arita K, Kurisu K, Tominaga A, Kawamoto H, Iida K, Mizoue T, et al. Transsellar color Doppler ultrasonography during transsphenoidal surgery. Neurosurgery (1998) 42(1):81-5. doi: 10.1097/00006123-199801000-00016

67. Ishikawa M, Ota Y, Yoshida N, Iino Y, Tanaka Y, Watanabe E. Endonasal ultrasonography-assisted neuroendoscopic transsphenoidal surgery. Acta Neurochir (2015) 157(5):863-8. doi: 10.1007/s00701-015-2382-z

68. Solheim O, Selbekk T, Løvstakken L, Tangen GA, Solberg OV, Johansen TF, et al. Intrasellar ultrasound in transsphenoidal surgery: a novel technique. Neurosurgery (2010) 66(1):173-85. doi: 10.1227/01.NEU.0000360571. $11582.4 \mathrm{~F}$

69. Solheim O, Johansen TF, Cappelen J, Unsgård G, Selbekk T. Transsellar Ultrasound in Pituitary Surgery With a Designated Probe: Early Experiences. Oper Neurosurg (2016) 1;12(2):128-34. doi: 10.1227/NEU.0000000000001108

70. Marcus HJ, Vercauteren T, Ourselin S, Dorward NL. Intraoperative Ultrasound in Patients Undergoing Transsphenoidal Surgery for Pituitary Adenoma: Systematic Review. World Neurosurg (2017) 106:680-5. doi: 10.1016/j.wneu.2017.07.054

71. Alomari A, Jaspers C, Reinbold WD, Feldkamp J, Knappe UJ. Use of intraoperative intracavitary (direct-contact) ultrasound for resection control in transsphenoidal surgery for pituitary tumors: evaluation of a microsurgical series. Acta Neurochir (2019) 161(1):109-17. doi: 10.1007/s00701-018-3747-x

72. Alshareef M, Lowe S, Park Y, Frankel B. Utility of intraoperative ultrasonography for resection of pituitary adenomas: a comparative retrospective study. Acta Neurochir (2021). doi: 10.1007/s00701-020-04674-2

73. Buchfelder M, Schlaffer SM. Novel Techniques in the Surgical Treatment of Acromegaly: Applications and Efficacy. Neuroendocrinology (2016) 103 (1):32-41. doi: 10.1159/000441980

74. Soto-Ares G, Cortet-Rudelli C, Assaker R, Boulinguez A, Dubest C, Dewailly D, et al. MRI protocol technique in the optimal therapeutic strategy of nonfunctioning pituitary adenomas. Eur J Endocrinol (2002) 146(2):179-86. doi: $10.1530 /$ eje. 0.1460179

75. Fernandez-Miranda JC, Zwagerman NT, Abhinav K, Lieber S, Wang EW, Snyderman $\mathrm{CH}$, et al. Cavernous sinus compartments from the endoscopic endonasal approach: anatomical considerations and surgical relevance to adenoma surgery. J Neurosurg (2018) 129(2):430-41. doi: 10.3171/ 2017.2.JNS162214

76. Kurwale NS, Ahmad F, Suri A, Kale SS, Sharma BS, Mahapatra AK, et al. Postoperative pituitary apoplexy: preoperative considerations toward preventing nightmare. Br J Neurosurg (2012) 26(1):59-63. doi: 10.3109/ 02688697.2011.591947

77. Zaidi HA, De Los Reyes K, Barkhoudarian G, Litvack ZN, Bi WL, RinconTorroella J, et al. The utility of high-resolution intraoperative MRI in endoscopic transsphenoidal surgery for pituitary macroadenomas: early experience in the Advanced Multimodality Image Guided Operating suite. Neurosurg Focus (2016) 40(3):E18. doi: 10.3171/2016.1.FOCUS15515

78. Askeland C, Solberg OV, Bakeng JB, Reinertsen I, Tangen GA, Hofstad EF, et al. CustusX: an open-source research platform for image-guided therapy. Int J Comput Assist Radiol Surg (2016) 11(4):505-19. doi: 10.1007/s11548015-1292-0

79. Arlt F, Chalopin C, Müns A, Meixensberger J, Lindner D. Intraoperative 3D contrast-enhanced ultrasound (CEUS): a prospective study of 50 patients with brain tumours. Acta Neurochir (2016) 158(4):685-94. doi: 10.1007/s00701016-2738-z

80. Maldaun MVC, Khawja SN, Levine NB, Rao G, Lang FF, Weinberg JS, et al. Awake craniotomy for gliomas in a high-field intraoperative magnetic 
resonance imaging suite: analysis of 42 cases. J Neurosurg (2014) 121(4):810-7. doi: 10.3171/2014.6.JNS132285

81. Duffau H, Capelle L, Denvil D, Sichez N, Gatignol P, Taillandier L, et al. Usefulness of intraoperative electrical subcortical mapping during surgery for low-grade gliomas located within eloquent brain regions: functional results in a consecutive series of 103 patients. J Neurosurg (2003) 98(4):764-78. doi: 10.3171/jns.2003.98.4.0764

82. Perin A, Prada FU, Moraldo M, Schiappacasse A, Galbiati TF, Gambatesa E, et al. USim: A New Device and App for Case-Specific, Intraoperative Ultrasound Simulation and Rehearsal in Neurosurgery. A Preliminary Study Oper Neurosurg (2018) 14(5):572-8. doi: 10.1093/ons/opx144

83. Singh V, Shaikh S, Shetty P, Moiyadi A. Customized Low-Cost Model for Hands-on Training in Intraoperative Ultrasound for Neurosurgeons: Our Experience and Review of Literature. World Neurosurg (2020) 143:564-71.e2. doi: 10.1016/j.wneu.2020.07.044

84. Vavruska J, Buhl R, Petridis AK, Maslehaty H, Scholz M. Evaluation of an intraoperative ultrasound training model based on a cadaveric sheep brain. Surg Neurol Int (2014) 9(5):46. doi: 10.4103/2152-7806.130314

85. Moiraghi A, Prada F, Delaidelli A, Guatta R, May A, Bartoli A, et al. Navigated Intraoperative 2-Dimensional Ultrasound in High-Grade Glioma Surgery: Impact on Extent of Resection and Patient Outcome. Oper Neurosurg (2020) 18(4):363-73. doi: 10.1093/ons/opz203

86. Sweeney JF, Smith H, Taplin A, Perloff E, Adamo MA. Efficacy of intraoperative ultrasonography in neurosurgical tumor resection.
J Neurosurg Pediatr (2018) 21(5):504-10. doi: 10.3171/2017.11. PEDS17473

87. Fountain DM, Bryant A, Barone DG, Waqar M, Hart MG, Bulbeck H, et al. Intraoperative imaging technology to maximise extent of resection for glioma: a network meta-analysis. Cochrane Database Syst Rev (2021) 1:CD013630. doi: 10.1002/14651858.CD013630.pub2

88. Iversen DH, Wein W, Lindseth F, Unsgård G, Reinertsen I. Automatic Intraoperative Correction of Brain Shift for Accurate Neuronavigation. World Neurosurg (2018) 120:e1071-8. doi: 10.1016/j.wneu.2018.09.012

89. Riva M, Hiepe P, Frommert M, Divenuto I, Gay LG, Sciortino T, et al. Intraoperative Computed Tomography and Finite Element Modelling for Multimodal Image Fusion in Brain Surgery. Oper Neurosurg (2020) 18(5):531-41. doi: 10.1093/ons/opz196

Conflict of Interest: The authors declare that the research was conducted in the absence of any commercial or financial relationships that could be construed as a potential conflict of interest.

Copyright () 2021 Šteño, Buvala, Babková, Kiss, Toma and Lysak. This is an openaccess article distributed under the terms of the Creative Commons Attribution License (CC BY). The use, distribution or reproduction in other forums is permitted, provided the original author(s) and the copyright owner(s) are credited and that the original publication in this journal is cited, in accordance with accepted academic practice. No use, distribution or reproduction is permitted which does not comply with these terms. 